\title{
Aircraft-borne, laser-induced fluorescence instrument for the in situ detection of hydroxyl and hydroperoxyl radicals
}

\author{
P. O. Wennberg, R. C. Cohen, N. L. Hazen, L. B. Lapson, N. T. Allen, T. F. Hanisco, \\ J. F. Oliver, N. W. Lanham, J. N. Demusz, and J. G. Anderson \\ Department of Chemistry and the Department of Earth and Planetary Sciences, Harvard University, \\ Cambridge, Massachusetts 03138
}

(Received 17 January 1994; accepted for publication 4 March 1994)

\begin{abstract}
The odd-hydrogen radicals $\mathrm{OH}$ and $\mathrm{HO}_{2}$ are central to most of the gas-phase chemical transformations that occur in the atmosphere. Of particular interest is the role that these species play in controlling the concentration of stratospheric ozone. This paper describes an instrument that measures both of these species at volume mixing ratios below one part in $10^{14}$ in the upper troposphere and lower stratosphere. The hydroxyl radical $(\mathrm{OH})$ is measured by laser induced fluorescence at $309 \mathrm{~nm}$. Tunable UV light is used to pump $\mathrm{OH}$ to the first electronic state $\left(\tilde{A}^{2} \Sigma^{+}\left(v^{\prime}=1\right) \leftarrow \tilde{X}^{2} \Pi_{3 / 2}\left(v^{\prime \prime}=0\right)\right)$ near $282 \mathrm{~nm}$. The laser light is produced by a high-repetition rate pulsed dye-laser powered with all solid-state pump lasers. $\mathrm{HO}_{2}$ is measured as $\mathrm{OH}$ after gas-phase titration with nitric oxidc. Measurements aboard a NASA ER-2 aircraft demonstrate the capability of this instrument to perform reliably with very high signal-to-noise ratios $(>30)$ achieved in short integration times $(<20 \mathrm{sec})$.
\end{abstract}

\section{INTRODUCTION}

No single measurement has so eluded the atmospheric chemistry community as has the detection of the hydroxyl radical. ${ }^{1,2}$ This is certainly not for lack of interest or for want of trying. In the troposphere and lower stratosphere, $\mathrm{OH}$ largely defines the oxidative power of the atmosphere. ${ }^{3-5}$ In the stratosphere, as was recognized as early as $1950,{ }^{6}$ processes involving $\mathrm{OH}$ and $\mathrm{HO}_{2}$, the hydroperoxyl radical, are directly and indirectly responsible for ozone destruction.? This paper describes the design of and initial results from an instrument built to detect both of these species. Although the instrument was built specifically to address the issue of the ozone photochemistry of the lower stratosphere, preliminary results suggest that the technique should be viable throughout most of the lower atmosphere.

$\mathrm{OH}$ is produced in the stratosphere primarily as a result of the photolysis of ozone and nitric acid:

$$
\begin{aligned}
& \mathrm{O}_{3}+h \nu(\lambda \leqslant 320 \mathrm{~nm}) \rightarrow \mathrm{O}\left({ }^{1} D\right)+\mathrm{O}_{2}\left({ }^{1} \Delta_{g}\right) \\
& \mathrm{O}\left({ }^{1} D\right)+\mathrm{H}_{2} \mathrm{O} \rightarrow \mathrm{OH}+\mathrm{OH}, \\
& \mathrm{HNO}_{3}+h \nu(200 \mathrm{~nm} \leqslant \lambda \leqslant 320 \mathrm{~nm}) \rightarrow \mathrm{OH}+\mathrm{NO}_{2} .
\end{aligned}
$$

In the lower stratosphere $(10-20 \mathrm{~km})$, results from this instrument now show conclusively ${ }^{8}$ that the catalytic destruction of ozone is dominated by the odd hydrogen radicals $\left(\mathrm{HO}_{x}\right.$ represents the sum of $\mathrm{OH}, \mathrm{HO}_{2}$, and $\left.\mathrm{H}\right)$ through the cycle:

$$
\begin{aligned}
& \mathrm{OH}+\mathrm{O}_{3} \rightarrow \mathrm{HO}_{2}+\mathrm{O}_{2} \\
& \mathrm{HO}_{2}+\mathrm{O}_{3} \rightarrow \mathrm{OH}+\mathrm{O}_{2}+\mathrm{O}_{2}
\end{aligned}
$$

Net: $\mathrm{O}_{3}+\mathrm{O}_{3} \rightarrow \mathrm{O}_{2}+\mathrm{O}_{2}+\mathrm{O}_{2}$.

Despite the important role played by $\mathrm{OH}$ and $\mathrm{HO}_{2}$, very few measurements of their atmospheric abundance have been made. Detection is difficult because of the very low concentrations (typically below one part per trillion for $\mathrm{OH}$ ). Sampling of $\mathrm{OH}$ and $\mathrm{HO}_{2}$, as with any free radical, is challenging because of their high surface reactivity. Additionally, in situ stratospheric observations of almost any trace species present a challenge because of the difficulty of operation on the available platforms-scientific balloons and high performance aircraft.

Stratospheric measurements of $\mathrm{OH}$ and $\mathrm{HO}_{2}$ have been made from ground-based and from balloon-borne payloads. The first in situ measurements of $\mathrm{OH}$ were make by Anderson et al. in the upper stratosphere and lower mesosphere $(40-70 \mathrm{~km})$ by solar-induced fluorescence in a rocket-borne experiment. ${ }^{9}$ Later, Anderson et al. used resonance fluorescence from a rf-excited lamp to measure $\mathrm{OH}$ (Ref. 10) and $\mathrm{HO}_{2}$ (following titration with $\mathrm{NO}$ ) in the mid-stratosphere $(30-40 \mathrm{~km}) .{ }^{11}$ A profile of $\mathrm{HO}_{2}$ in the mid and upper stratosphere (altitude $>35 \mathrm{~km}$ ) has been reported from the ground-based millimeter wave instrument of De Zafra et al. ${ }^{12}$ Sub-millimeter and far infrared detection of $\mathrm{OH}$ (Refs. 13 and 14) and $\mathrm{HO}_{2}$ (Refs. 13, 15, and 16) from halloon-borne platforms have also been reported. In the only attempt to collect free radicals in the stratosphere, a matrix isolation/electron-spin resonance technique has been used to attempt to detect stratospheric $\mathrm{HO}_{2} \cdot{ }^{17}$ Laser-based fluorescence measurements of $\mathrm{OH}$ have been performed by the laser imaging, detection, and ranging technique (LIDAR). ${ }^{18,19}$ Finally, the progenitor of the instrument described here measured $\mathrm{OH}$ (and $\mathrm{HO}_{2}$ after chemical conversion) down to 23 $\mathrm{km}$ by in situ laser-induced fluorescence (LIF) from a balloon-borne gondola during three summer flights in 1987, 1988 , and 1989..$^{20-22}$

Although these experiments provided a crucial first look at the $\mathrm{HO}_{x}$ abundance in the stratosphere, as a test of stratospheric chemistry each suffered to some degree from the lack of sufficient correlative measurements. Interpretation of $\mathrm{HO}_{x}$ measurements in the absence of simultaneous determination 


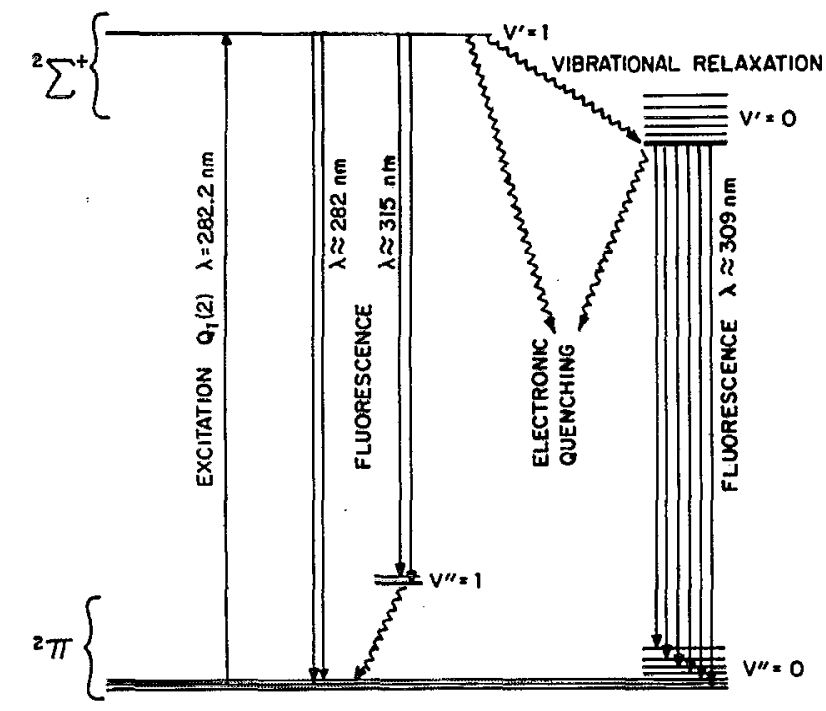

FIG. 1. Spectroscopy and energy transfer in the LIF detection of $\mathrm{OH} . \mathrm{OH}$ ( $\left.{ }^{2} \Pi_{3 / 2}, N^{n}=2\right)$ is pumped via the $Q_{1}(2)$ and $Q_{2 I}(2)$ transitions to the first vibrationally-excited level of the $A$ state $\left({ }^{2} \Sigma^{+}\left(v^{\prime}=1\right)\right)$ near $282 \mathrm{~nm}$. Redshifted fluorescence is observed following relaxation to the vibrational ground state.

of the important chemical sources and sinks--such as the oxides of nitrogen $\left(\mathrm{NO}, \mathrm{NO}_{2}, \mathrm{HNO}_{3}\right.$ ), carbon monoxide, ozone, and water vapor-is notoriously difficult. ${ }^{23,13}$

The instrument described in this paper represents the first aircraft-borne instrument that produces results of high enough quality-in combination with measurements of most of the photochemically active species--to provide a real test of our understanding of the odd-hydrogen photochemistry of the lower atmosphere. $\mathrm{OH}$ and $\mathrm{HO}_{2}$ measurements with signal-to-noise ratio of over 30 are produced with short integration times. The new $\mathrm{HO}_{x}$ measurement capability augments a suite of in situ instruments aboard the NASA ER-2 aircraft that is capable of detecting, simultaneously, most of the species thought to be important in controlling the concentration of ozone in the lower stratosphere.

\section{LIF AND THE DETECTION OF ATMOSPHERIC OH}

The laser-induced-fluorescence technique is unrivaled for making sensitive and selective concentration measurements of the hydroxyl radical. Typically, a frequencydoubled dye laser is tuned to one of the rovibronic absorption features in the $\tilde{A}^{2} \Sigma^{+} \leftarrow-\tilde{X}^{2} \Pi$ electronic transition. Fluorescence from the excited state is then observed with a photo-multiplier tube. Figure 1 shows the excitation scheme employed in this work. Also shown are the competing deactivation processes that occur following laser excitation. $\mathrm{OH}$ $\left({ }^{2} \Pi_{3 / 2}, N^{\prime \prime}=2\right)$ is pumped via the $Q_{1}(2)$ or $Q_{21}(2)$ transition to the first vibrationally excited level of the $\tilde{A}$ state $\left({ }^{2} \Sigma^{+}\left(v^{\prime}=1\right)\right)$ at $35442 \mathrm{~cm}^{-1}(282 \mathrm{~nm})$. In air, (for pressures above a few torr) approximately 75 percent of the excited OII molecules undergo vibrational energy transfer to $v^{\prime}=0$. Fluorescence is then observed from the manifold of rotational levels of $v^{\prime}=0$ near $309 \mathrm{~nm}$. Competing with fluorescence is the efficient electronic quenching resulting from collisions; at ER-2 cruise altitudes $(20 \mathrm{~km}), 99$ percent of the relaxation is non-radiative. Despite the low fluorescence quantum yield, very high signal-to-noise measurements can be made. The instrument described here is capable of measuring $\mathrm{OH}$ concentrations below 50,000 molecules $\mathrm{cm}^{-3}$ in the lower stratosphere. In a low-pressure flow tube (during laboratory calibration) concentrations below 500 molecules $\mathrm{cm}^{-3}$ have been detected with this instrument.

While laboratory studies employing OH LIF are ubiquitous, application of the technique to atmospheric monitoring has had a troubled and tortuous history. Early attempts were plagued by poor signal-to-noise and a crippling interference problem. ${ }^{24-27}$ Just as the atmospheric source of hydroxyl radicals involves the UV photolysis of ozone followed by the reaction of the $O\left({ }^{1} D\right)$ with water vapor [reaction (1)], the same chemistry can occur in the laser beam. This process is very fast; $\mathrm{OH}$ can be produced and detected in the same 10 ns laser pulse. Unless great care is taken, concentrations of $\mathrm{OH}$ produced in this manner can be orders of magnitude higher than the ambient levels. A recent review has been published that discusses the problem in detail. ${ }^{28}$

The instrument described here does not suffer from this interference for a number of reasons. Signal rales from laser generated $\mathrm{OH}$ will depend quadratically on the laser pulse energy. By combining high-pulse-repetition rates with low pulse energies, it is possible to greatly reduce the concentration of $\mathrm{OH}$ produced by the laser beam while maintaining high sensitivity. Although the average UV power used (of order $10 \mathrm{~mW}$ ) is similar to earlier LIF experiments, the pulse repetition rates used are orders of magnitude higher $(6 \mathrm{kHz}$ compared to $10 \mathrm{~Hz}$ ) and thus the pulse energies are orders of magnitude lower. Additionally, the aridity of the stratosphere further reduces the interference (relative to that expected in the troposphere), which scales as the mixing ratio of water vapor.

Several diagnostics were incorporated into the instrument to test for photochemical interference. (1) The laser power is varied during flight to test that retrieved $\mathrm{OH}$ densities are independent of laser pulse energy. (2) Ambient $\mathrm{OH}$ is removed from the air by addition of a chemical scrubber, perfluoropropene $\left(\mathrm{C}_{3} \mathrm{~F}_{6}\right)$. The gas is added in concentrations sufficient to remove the ambient $\mathrm{OH}$ on time scales of milliseconds. This does not, however, affect the laser-generated $\mathrm{OH}$, the chemistry of which takes place in nanoseconds. (3) Measurements made during night-time, when no $\mathrm{OH}$ is expected to be present, yield an upper limit to $\mathrm{OH}$ generated by the laser. These results have shown that fewer than $1 \times 10^{4}$ $\mathrm{OH}$ molecules $\mathrm{cm}^{-3}$ are produced by the laser in the lower stratosphere.

\section{MEASUREMENT OF $\mathrm{HO}_{2}$}

The hydroperoxyl radical is measured after conversion to $\mathrm{OH}$ by the bimolecular reaction with nitric oxide. ${ }^{11,22,29}$ Although oxygen-atom extraction is quite fast,

$$
\mathrm{HO}_{2}+\mathrm{NO} \rightarrow \mathrm{OH}+\mathrm{NO}_{2}
$$

one-to-one conversion of $\mathrm{HO}_{2}$ to $\mathrm{OH}$ is not possible because of the production of HONO:

$$
\mathrm{OH}+\mathrm{NO} \rightarrow \mathrm{HONO} \text {. }
$$


Because reaction (5) is only four times faster than reaction (6) in the lower stratosphere, peak $\mathrm{OH}$ densities are lower than 70 percent of the sum of the initial $\mathrm{OH}$ and $\mathrm{HO}_{2}$ concentrations. As is discussed in detail later, retrieval of the $\mathrm{HO}_{2}$ concentrations requires accurate diagnoses of the kinetics of the titration during flight. Variable concentrations of nitric oxide are added to the air flow, the velocity of which is also varied under computer control. Additionally, the $\mathrm{OH}$ concentration is mcasured at two locations down-stream of the NO injector as a further diagnostic of the conversion process.

Interferences: Because $\mathrm{HO}_{2}$ is not directly observable, any reactions (or reaction sets) that produce $\mathrm{OH}$ from the addition of NO must be considered as a potential interference. Oxygen-atom extraction from alkylperoxy radicals by NO produce the alkoxy radicals; which can react in turn with $\mathrm{O}_{2}$ to produce $\mathrm{HO}_{2}$. In the lower stratosphere, only the methylpcroxy radical needs to be considered.

$$
\begin{aligned}
& \mathrm{CH}_{3} \mathrm{OO}+\mathrm{NO} \rightarrow \mathrm{CH}_{3} \mathrm{O}+\mathrm{NO}_{2} \\
& \mathrm{CH}_{3} \mathrm{O}+\mathrm{O}_{2} \rightarrow \mathrm{CH}_{2} \mathrm{O}+\mathrm{HO}_{2} \\
& \mathrm{HO}_{2}+\mathrm{NO} \rightarrow \mathrm{OH}+\mathrm{NO}_{2} .
\end{aligned}
$$

The overall efficiency of this reaction set is only 50 percent that of $\mathrm{HO}_{2}$ conversion due to the fast three-body formation rate of alkyl nitrites, $\mathrm{CH}_{3} \mathrm{ONO}$. In the stratosphere, methylperoxy concentrations are predicted to be a factor of ten smaller than $\mathrm{HO}_{2}$, and as a result this interference should be essentially negligible.

\section{HARDWARE DESCRIPTION}

The $\mathrm{HO}_{x}$ instrument resides in the nose of a NASA ER-2 high-altitude aircraft. The location was chosen because it provides both the volume and weight carrying capabilities required as well as access to air flow stream-lines unperturbed by the aircraft. The following is a detailed description of hardware. is

Numerous issues had to be addressed during the course of the design work:

Air sampling. Flow of air into the detection region must be done in a "wall-less" manner. OH radicals are lost with near unity reaction probability on the walls, which are painted black to reduce the infiltration of sunlight into the detection optics. A two-ducted inlet system was incorporated into the design to meet these criteria:

Laser subsystem. A narrow-bandwidth tunable UV laser is required. High pulsc-rcpetition rates with average power greater than $10 \mathrm{~mW}$ are needed to make high signal-to-noise measurements of the sub-parts per trillion concentrations of $\mathrm{OH}$. Additionally, there are severe weight and volume constraints. The laser subsystem, employing solid-state laser technology, was designed into a space of less than $0.2 \mathrm{~m}^{3}$.

Detection axes. The fluorescence detection axes were designed to have large throughput while heavily discriminating against sunlight and laser scatter. Additionally, the walls at the optical interfaces were designed to have minimal impact on the flow characteristics within the air-sampling duct.
Gas handling. The measurement of $\mathrm{HO}_{2}$ requires that nitric oxide (NO) be added to the air sample upstream of the LIF axes. The NO needs to be metered into the flow in a controlled way in order to carefully diagnose the titration kinetics. Nitric oxide presents a serious safety hazard. The hardware was specifically designed to address the safety issues both for in-flight handling and ground operation.

Command/control. The experiment is expected to work unattended for 8 hours. Only minimal interaction with the instrumentation by the pilot is allowed-typically a single on/off switch. This presents a challenge to the instrument design. All flight algorithms were preplanned. A real-time multi-tasking operating system was used to control the experiment using a personal computer.

Aircraft accommodation. Adaptation to the space and configuration represented by the ER-2 nose influenced every aspect of the design. Providing adequate access to the instrument during installation, maintenance, and test is mandatory: In addition, the instrument must be able to perform through a wide range in temperature (potentially in excess of $100^{\circ} \mathrm{C}$ ) and pressure $(0.25-1$ bar). Air needed to be ducted through at high mass flows without leakage. Power is derived from the aircraft busses and has to be conditioned for instrument use.

Weight. Although the ER-2 nose is capable of carrying nearly $300 \mathrm{~kg}$, restrictions on the total aircraft payload require that the total weight of the instrument be below $220 \mathrm{~kg}$. The final weight of the instrument (including a correlative measurement of water vapor) is approximately $200 \mathrm{~kg}$.

Ground support equipment. The GSE was designed to allow facile servicing of the instrument and quick turnaround of the data. Typically, a flight series is comprised of many flights spaced as closely as 36 hours. Measured $\mathrm{OH}$ and $\mathrm{HO}_{2}$ mixing ratios are expected to be available to other experimenters within 6 hours of landing.

\section{A. Sampling}

Figure 2 is a schematic drawing showing the airflow through the instrument. The design of the ducting borrows heavily from the Harvard $\mathrm{ClO}$ experiment located in the port wingpod of the ER-2. ${ }^{30.31}$ Air enters the nose through a 15 $\mathrm{cm}$ inlet designed to prevent shock or separation of the boundary layer as the air is decelerated from free stream (200 $\mathrm{m} / \mathrm{s}$ ) to approximately $100 \mathrm{~m} / \mathrm{s}$. Toward the back of the entrance duct, the growth of the thermal boundary layer is observed with an array of small bead thermistors.

The laminar core of the flow then passes into the square $7.5 \times 7.5 \mathrm{~cm}$ detection duct. A pneumatically-powered gate valve can scal off this duct to prevent water vapor from entering and condensing on the walls and optical surfaces during ascent and descent through the troposphere. The rest of the air in the entrance duct is bypassed and exhausted out of the plane through a louvered hatch at the top. During early test flights, a throttle valve and velocity sensing equipment provided for modulating the bypass flow. To save weight, this hardware was subsequently removed after the data demonstrated that the flow characteristics in the detection duct were not affected by velocity variations in the bypassed flow.

The velocity in the detection duct can be varied from 


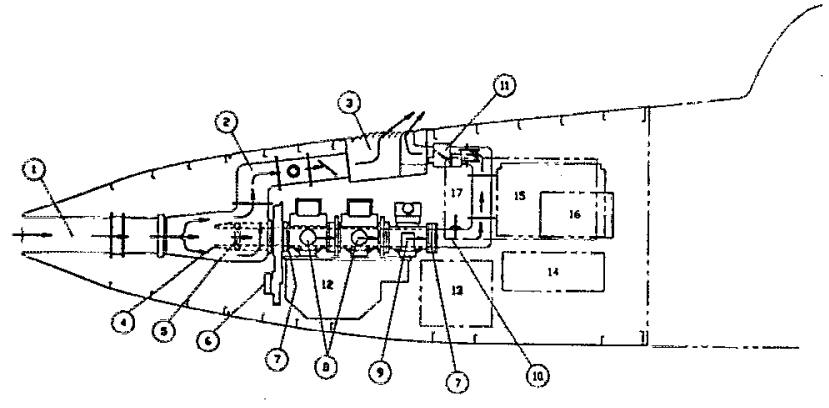

FIG. 2. Air flow within the $\mathrm{HO}_{x}$ instrument. A double-ducted design is used to channcl boundary-layer-free air into the detection axes. Air enters the nose through the large entrance duct 1 . Most of the air is diverted through the bypass duct 2 and exhausted into a plenum 3 and out of the airframe. The laminar corc of the entrance flow is sampled into the detection duct 4. Small, perforated Teflon tubes 5 are used to inject nitric oxide into the flow for the measurcment of $\mathrm{HO}_{2}$. The detection duct can be closed using a pneumatically-powered gate valve 6 . Small bead thermistors 7 are used to measure the growth of the thermal boundary layer in the duct before and after the $\mathrm{OH}$ detection axes $\mathbf{8}$. An ancillary measurement of water vapor 9 is made following the $\mathrm{OH}$ detection axes. Velocity in the ducts is measured with pitôt tubes 10 and can be controlled with throttle valves 11. Also shown in this figure are the locations of: the laser assembly 12 and laser power supply 13 , computer 14 and interface card cage 15 , frequency reference cell 16 , and main power supply 17 .

between 20 and $100 \mathrm{~m} / \mathrm{s}$ by means of a throttle valve located just before the exhaust. This stepper-motor driven butterfly valve also serves to complete the seal of the detection duct during ascent and descent. A pitot tube is used to measure the static pressure and velocity. Pressure is monitored using 1000 torr capacitance manometers (MKS Inst., Andover, $\mathrm{MA}$ ) and a 10 torr differential transducer of the same manufacture. The gauges are contained in a thermostatically temperature-regulated enclosure. Approximately $11.5 \mathrm{~cm}$ after the entrance to the detection duct a grill of small, perforated teflon tubes crosses the flow. These tubes are used to add nitric oxide into the flow for the detection of $\mathrm{HO}_{2}$. The Reynolds number with respect to the tube diameter is quite large $(>500)$ and it is expected that large $(5 \mathrm{~mm})$ wake vortices will form behind the injector. ${ }^{32}$ This serves to mix the NO into the flow quickly. It is likely, however, that the turbulence induced by the injectors will cause the flow in the duct to become turbulent prematurely, resulting in faster boundary layer growth. Indeed, during test flights, $\mathrm{OH}$ losses of greater than 25 percent were observed at velocities below $20 \mathrm{~m} / \mathrm{s}$. At these slow flow rates, growth of the thermal boundary layer into the core of the flow was observed. Measured $\mathrm{OH}$ densities were found, however, to be independent of flow velocity for speeds above $40 \mathrm{~m} / \mathrm{s}$.

\section{B. Laser system}

The instrument's optical system is comprised of two major assemblies. The heart of the instrument is the pulsed dyelaser system designed and built in our laboratory. A schematic drawing of the design is shown in Fig. 3. The optical stability of this system is crucial to the performance of the instrument as a whole. To that end, the laser assembly is structurally autonomous, very compactly packaged, and independently housed, heated, and insulated. Within the laser assembly, the two solid state pump lasers are mounted, base-

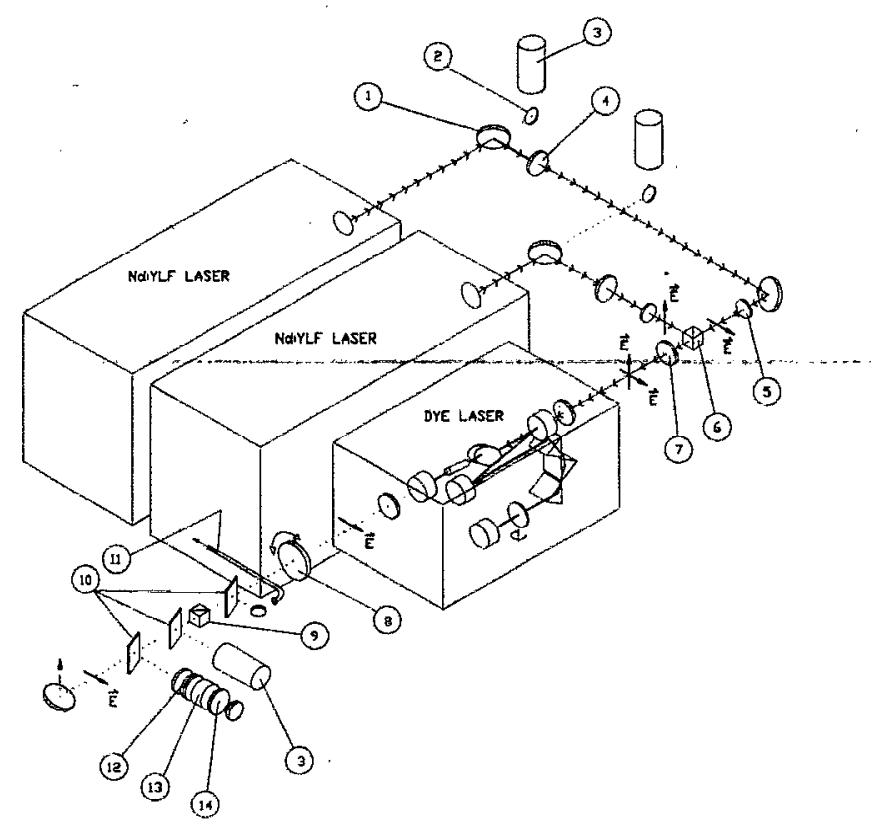

FIG. 3. Schematic of the pulsed UV dye laser system. The dye laser is powered by two frequency-doubled Nd:YLF lasers (see Fig. 4) contained in sealed pressure vessels. The small light leakage through the turning mirrors $\mathbf{1}$ is scattered off a quartz defuser $\mathbf{2}$ and used to monitor (with amplified photodiodes 3) the Nd:YLF output. The beams are collimated 4, and the polarization of the pump lasers are rotated with half-wave plates 5 . The two lasers are combined on a polarization beam splitter 6 , before being focused 7 into the dye laser (see Fig. 5). Following the dye-laser, a half-wave plate 8 , is used in conjunction with a polarization analyzer 9 to provide attenuation of the UV output of the dye laser. Three samples of the UV output beam are taken with 45 degree quartz beam splitters 10 . The first is launched into a fiber $\mathbf{1 1}$ and sent to a frequency reference cell (see Fig. 6). The second is used to monitor the output power with an amplified photodiode 3 . The final sample is filtered 12 and sent through a high-finesse etalon 13 , and pinhole 14 , before being measured with a photodiode as a diagnostic of the laser linewidth.

to-base, on a single plate of a box structure, the opposite face of which supports the dye laser. The coupling optics are also incorporated onto the box faces for enhanced stability.

In the upper portion of the optical system, the detection axes and associated flow tube (discussed later) are attached to the airframe and achieve temperatures in flight that are largely controlled by the temperature of the ambient air flowing through the structure. The two assemblies are joined with thermally isolating spacers at a single hard point near where the UV beam passes between them and at three other points where slide mounts are used. This is done to avoid thermal deformation of the laser structure due to the very large and variable thermal gradients that exist between the two assemblies $\left(>60^{\circ} \mathrm{C}\right)$.

\section{The Nd:YLF lasers}

Two solid-state $\mathrm{Nd}^{3+}$ :YLF lasers (TFR, SpectraPhysics-Laser Diode Systems, Mountain View, CA) are used to power the dye laser. A ten-watt diode bar is used to pump a $\mathrm{Nd}^{3+}$ :YLF crystal located in a tightly folded cavity (Fig. 4). An electro-optic Q-switch is added before the output coupler to allow for pulsed operation. 


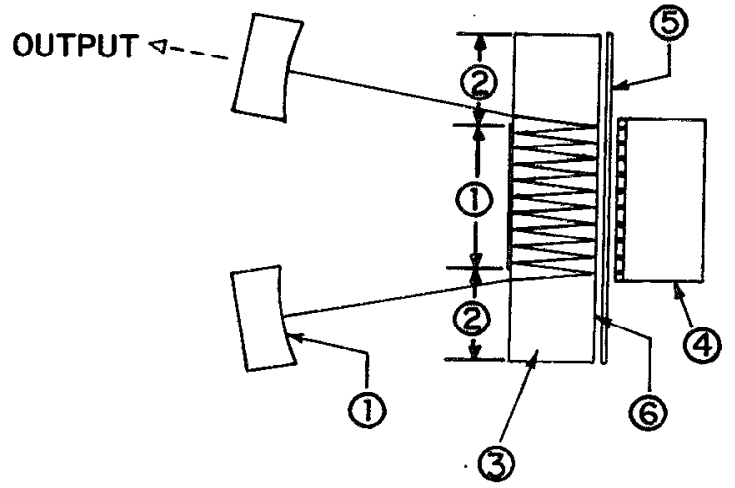

FIG. 4. Cavity design of the tightly folded resonator (Spectra Physies, Laser Diode Systems, Mountain View, CA). Light from a $10 \mathrm{~W}$ diode laser bar 4 is focused with a fiber lens $\mathbf{5}$ onto the Nd:YLF block $\mathbf{3}$. The surface is coated for maximum reflectivity at $1047 \mathrm{~nm}$ and minimum reflectivity at the pump wavelength $-800 \mathrm{~nm}$. High reflectivity coatings on the end mirror and opposite the diode bar 1 , as well as anti-reflection coating of the other transmissive surfaces 2 result in very high gain for this cavity design. Pulsed operation is accomplished with the addition of an electro-optic $Q$-switch (not shown). Frequency doubling is performed outside the laser cavity.

This design results in very high gain and short pulse widths (5-10 ns). Frequency doubling of the infrared output is done external to the cavity in a lithium borate crystal (LBO). The lasers are used as received from Spectra-Physics with only a few modifications. A pressure vessel is used to enclose the laser heads since the high voltage circuitry associated with the $\mathrm{Q}$-switch fails at the reduced pressures characteristic of the ER-2 nose ( 3 psi above ambient). Additionally, the original lens used to recollimate the output from the doubling stage has been removed and replaced with a pair of wedges to correct for poor beam-pointing control during manufacture of the TFR. A separate recollimating lens has been added outside the pressure vessel.

The commercial power supply boards (Spectra-Physics) were repackaged, adapted to aircraft power, and supplemented with a control interface and triggering/delay board. The lasers are pulsed at $6 \mathrm{kHz}$ with a pulse delay of $25 \mathrm{~ns}$ between the output of the two lasers. Jitter is typically less than $5 \mathrm{~ns}$, which as discussed below has a direct impact on the frequency width of the dye laser. Each laser typically produces $450 \mathrm{~mW}$ of power at $523 \mathrm{~nm}$.

Output from the two lasers are cross polarized using zero-order half-wave plates (CVI Laser, Albuquerque, NM). The two beams are combined using a polarization beam splitting cube (CVI Laser, Albuquerque, NM) and focused into the dye laser. The good beam quality and pointing stability ( $<100 \mu$ rad movement) of the pump lasers is critical to obtaining stable dye laser performance. The optical performances of the pump lasers are monitored continuously by measuring the light leakage through two of the steering mirrors. Throughout the instrument, amplified photodiodes (UDT-555UV, United Detector, Hawthorne, CA) are used for laser photometry. These diodes are fitted with color-glass filters and quartz optical diffusers. In some instances, inconel coated neutral density (ND) filters are required to prevent saturation of the detectors. The quartz diffusers serve to

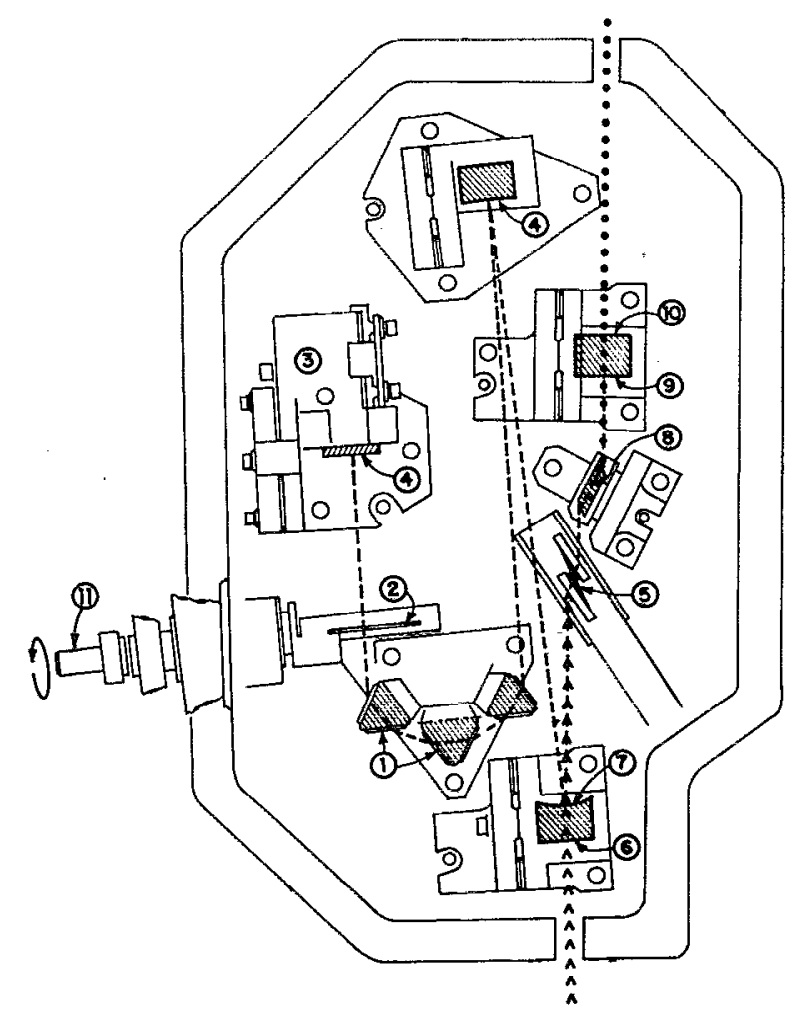

FIG. 5. Dye-laser cavity. This prism 1 and etalon 2 tuned cavity was chosen because of its low threshold, high efficiency, and proper frequency width. The green pump lasers $(>>>)$ pass through the anti-reflection coated entrance mirror 6 and into the dye cell 5 . The dye-laser fundamental, 564 $\mathrm{nm}(--)$, is expanded in an intracavity telescope 7-4. The coarse tuning mirror 4 is held in a temperature-compensated mount 3 , designed to correct for the change in the index of refraction of the prisms with temperature. UV $(\cdots)$ is produced in a BBO crystal 8 and exits the cavity through the end mirror which is coated for maximum reflectivity in the visible 9 and minimum reflectivity in the UV 9,10 . Fine frequency tuning is accomplished by rotation of the etalon 11 . Selection of the proper frequency is accomplished by pressure tuning the sealed cavity.

maintain the linearity of the detectors to higher flux levels as well as prevent the inconel ND filters from acting as etalons.

\section{The dye laser}

The basic design of the dye laser cavity is by Wallace, ${ }^{33}$ which was commercialized by Chromatix, Inc. (Mountain View, CA, no longer in operation). This cavity was chosen for its low pulse-energy threshold $(<20 \mu \mathrm{J})$ and for its frequency width, which (with the addition of an intra-cavity etalon) is ideally matched to the Doppler and pressurebroadened linewidth of the $\mathrm{OH}$ transition $\left(0.10-0.15 \mathrm{~cm}^{-1}\right)$. Additionally, the length of the cavity $(45 \mathrm{~cm})$ assures that many longitudinal modes will oscillate within the frequency envelope, providing for a relatively uniform spectral power distribution. This is important in preventing bleaching of the $\mathrm{OH}$ transition.

The cavity [see Fig. (5)] is longitudinally pumped with the dye $[0.2$ g/liter Pyrro-methene 567 (Exciton, Dayton, $\mathrm{OH}$ ) in isopropanol] flowing through a Brewster angle cell. This dye was found to produce 50 percent more UV than Rhodamine 6G. Dispersion is achieved with three Brewsterangle cut SF-10 prisms (ESCO Products, Inc., Oak Ridge, $\mathrm{NJ})$. This results in a laser linewidth of approximately 3 
$\mathrm{cm}^{-1}$ at $282 \mathrm{~nm}$. Further narrowing of the frequency width is achieved with an intra-cavity solid $0.5 \mathrm{~mm}$ etalon (Interoptics, Ontario, Canada) with a finesse of approximately 25. Output power is cut approximately in two and the frequency width is reduced to $0.098 \mathrm{~cm}^{-1}$. Intra-cavity frequency doubling occurs in a Brewster-angle cut barium borate crystal (BBO) of optical path $10 \mathrm{~mm}$ (Cleveland Crystal, Cleveland, $\mathrm{OH})$. The dye laser fundamental is diffraction limited with a beam waist (located at the output coupler) of approximately $0.2 \mathrm{~mm}$. Because type I frequency doubling is used, the UV is cross polarized with respect to the dye laser fundamental. Additionally, the output divergence is high due to the large walk-off angles for BBO.

Because the cavity has very low loss at the laser fundamental $(564 \mathrm{~nm})$, the same dye cell can be used as an amplifier. Due to the low pump pulse energy $(<100 \mu \mathrm{J})$ and the length of the cavity $(45 \mathrm{~cm})$, the laser does not reach threshold until some 20 ns after the arrival of the $\mathrm{Nd}^{3+}$ :YLF pulse. The poor energy-storage characteristics of the dye results in feeble output. Applying a second pulse after the cavity has reached threshold, however, causes the gain to become saturated at which point the conversion efficiency into the UV approaches $10 \%$. Frequency width narrowing of the wave packet occurs during the delay (the width will decrease as the square root of the number of passes through the etalon). As a result, careful control of the pulse timing is crucial to maintaining the linewidth stability of the output.

All optics, with the exception of the etalon, are mechanically fixed, with the most mechanically sensitive mounted on a heavy isothermal internal deck, which is physically isolated from the forces on the pressure housing. The knobs and handles used to adjust the mirror mounts are removed after final alignment is performed. This alignment has been stable during the last year of operation. Fine frequency tuning is accomplished by small rotations of the etalon. This very precise motion, requiring highly repeatable accuracy to 10 $\mu$-radians, is achieved by a fine-pitch lead screw and nut (New Focus, Mountain View, CA) flexure-coupled to a lever on the etalon support shaft, itself carefully mounted in angular contact bearings and sealed through the laser housing. The lead screw is coupled to a stepper motor (Parker Hannifin/Compumotor CT32-39, Rohnert Park, CA) operating in the microstep mode and employing a power-saver option to reduce heating in the vicinity of this sensitive drive. As with the other stepper systems in the instrument, the electronic drives are re-packaged commercial units (Intelligent Motion Systems, Taftville, CT).

The dye laser gain is maximized at the appropriate wavelength by varying the effective refractive index of the tuning prisms. A motor-actuated bellows (Parker Metal Bellows, Sharon, MA) allows tuning of the laser gain by controlling the sealed laser housing pressure $\left(0.3 \mathrm{~cm}^{-1} /\right.$ torr at $282 \mathrm{~nm}$ ). The welded-metal bellows, driven by a ball screw (Warner Electric, Beloit, WI) and geared stepper motor (Oriental/Vextra PX244, Torrence, CA), can provide a maximum range of \pm 30 torr variation on the housing absolute pressure; a "fail-safe" brake (Inertia Dynamics, Collinsville, CT) is engaged on the system during periods of inactivity.
The pressure is monitored with a small, one atmosphere pressure transducer (Micro Gage, El Monte, CA).

Temperature stability of the dye laser assembly is crucial to output stability. The dye laser housing is insulated, and also enclosed within the larger laser assembly housing, itself thermostatically controlled to $20 \pm 2{ }^{\circ} \mathrm{C}$. Two additional control methods are employed. First, the dye solution is thermally stabilized to $\pm 0.5^{\circ} \mathrm{C}$ using a thermoelectric cooling/ heating system and then passed through the dye cell and laser housing cover. Peltier devices (Marlow Industries, Dallas, TX) pass heat between the liquid loop and a finned heat exchanger inside the aircraft nose. Electronic bi-polar control (Alpha-Omega Instruments, Norton, MA) incorporates both differential and integral compensation. Second, in the standby condition the insulated housing is electronically heated with thermostatic control just below the operating temperature set point $\left(23 \pm 2{ }^{\circ} \mathrm{C}\right)$.

\section{UV output optics}

Before the laser light is sent to the detection axes, it passes through a series of optical components. Three 45degree beam-splitters (un-coated quartz) are used to sample the output. The first sample is sent through a fiber to the frequency-reference cell described below. The second pickoff is used to measure the average laser power with an amplified photodiode. This measurement is used to normalize the fluorescence signal to laser power. The last pickoff sends a fraction of the lascr through a normal-incidence highfinesse etalon (Interoptics, Ontario, Canada) before passing through a small pinhole and into a photodiode. During wavelength scans, this device is used to determine if any change occurs in the frequency width of the output.

A zero-order half-wave plate (CVI Laser, Albuquerque, $\mathrm{NM}$ ) located at the output of the dye-laser is used in combination with an optically-contacted dielectric-coated quartz polarization analyzer (Interoptics, Ontario, Canada) to allow in-flight attenuation of the laser. Rotation of the half-wave plate (and thus the laser polarization) is accomplished by a stepper-motor driven worm/worm gear arrangement providing high precision positioning and passive locking. Additionally, this device can be used to increase the laser power sent to the frequency reference cell since the beam splitter (whose reflectivity is very sensitive to polarization) is located between the half-wave plate and the analyzer. Extinction in excess of $10^{4}$ is achieved with this attenuator.

\section{Liquid handling}

Two closed-loop fluid systems are incorporated into the laser system. Both use positive displacement pumps operated at flow rates of 1-2 liters/min driven by magnetically coupled dc brushless motors (Micropump, Vancouver, WA). These are supplemented with reservoirs and thermoelectric heater/cooler systems with electronic bi-polar controllers. The dye loop has been described earlier. The other loop, for cooling the Nd:YLF laser heads, uses a solution of 40 percent ethylene glycol in distilled water and exchanges heat with free stream air through a heat exchanger mounted in a panel opening in the bottom skin of the nose. 


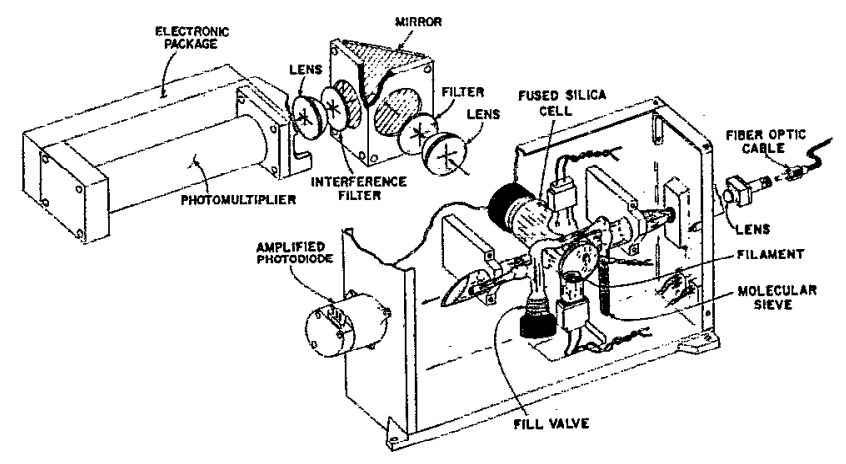

FIG. 6. OH frequency reference cell. LIF signal is observed in a low pressure quartz cell. A heated filament produces $\mathrm{OH}$ in an oxygen (4 torr) and water vapor environment. $\mathrm{H}_{2} \mathrm{O}$ partial pressure of 0.25 torr is maintained over a molecular sieve trap. A small fraction of the laser light is piped to the cell through a fiber optic. The UV power is monitored after passing through the cell with a photodiode. OH fluorescence is collimated, filtered, and focused onto a PMT operated in photon-counting mode.

\section{Performance}

Overall, the laser system proved to be very robust. Output power during flight is equal to ground performance. Typically, $15-20 \mathrm{~mW}$ of UV is produced with slow temporal variations of order 20 percent. The frequency width of the output is within 10 percent of the nominal $0.098 \mathrm{~cm}^{-1}$. The system provided over 100 hours of flawless operation during the NASA organized Stratospheric Photochemistry, Aerosols, and Dynamics Expedition (SPADE) campaign of April and May, 1993. Only slight degradation of the pump-laser output has been observed during the first 1000 hours of operation.

\section{Frequency reference cell}

Approximately one percent of the UV light is sent through a fiber to an $\mathrm{OH}$ reference cell. This device (shown in Fig. 6) is used as the fundamental frequency reference for feedback to the laser-wavelength control system. The laser light is sent through a low-pressure quartz cell where a small concentration of $\mathrm{OH}$ radicals $\left(10^{9}\right.$ molecules/cc $)$ are produced on a glowing NiChrome filament. ${ }^{34} \mathrm{~A}$ molecular-sieve trap maintains a partial pressure of water vapor of 0.25 torr. Every fifty hours of operation, the cell is recharged with a mixture of $\mathrm{O}_{2}$ (4 torr) and $\mathrm{N}_{2}$ (2 torr). Laser-induced fluorescence is observed at $310 \mathrm{~nm}$ with a filtered-PMT system. The power of the UV exiting the cell is measured with an amplified photodiode.

The $\mathrm{OH}$ fluorescence lifetime is used as a diagnostic of consumption of $\mathrm{O}_{2}$ by the cell. Immediately after filling, the fluorescence lifetime is quite short $(<100 \mathrm{~ns})$. The cell is refilled when approximately 50 percent of the $\mathrm{O}_{2}$ has been consumed (when the fluorescence lifetime has approximately doubled). Full depletion of oxygen has been observed during ground operation and results in complete loss of $\mathrm{OH}$ production by the filament. Presumably, the $\mathrm{O}_{2}$ is converted to metal oxides, which appears as a white, water-soluble film deposited on the walls. (The need for $\mathrm{O}_{2}$ refutes the suggestion by Fridell that $\mathrm{OH}$ is produced directly by the dissociation of water on the filament. ${ }^{35}$ ) The addition of $\mathrm{N}_{2}$ to the cell increases the LIF signal rates by aiding in the required

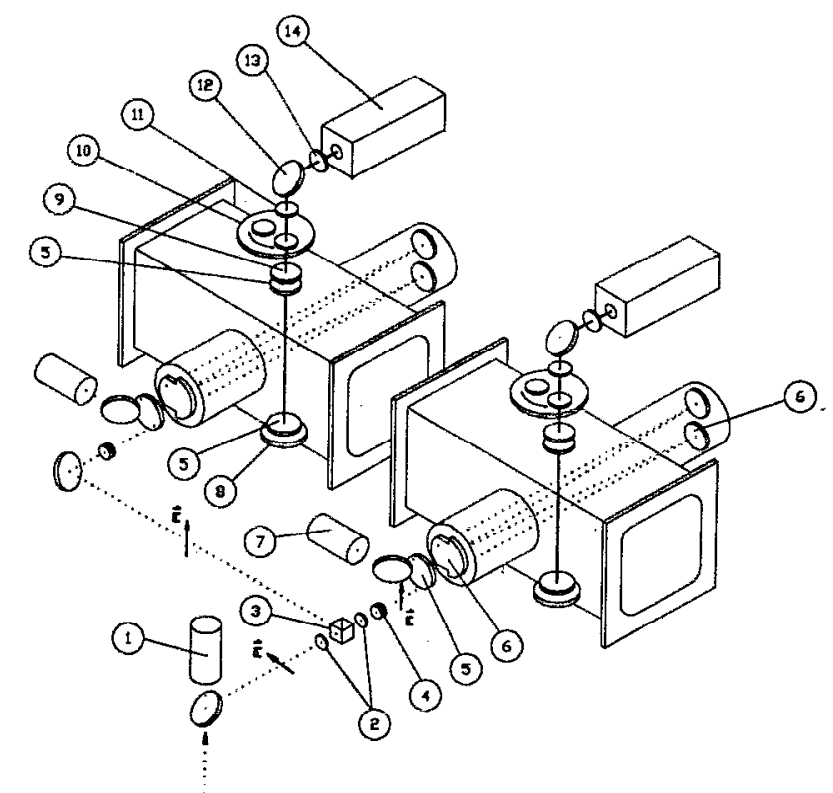

FIG. 7. The $\mathrm{OH}$ detection axes and feed optics. $\Lambda$ quadrant photo-detector 1 is used to monitor beam movement by observing the small fraction of the UV laser light that leaks through the first turning mirror. The UV beam is divided by use of half-wave plates 2 and a polarization-sensitive beam splitter 3 . The beams are sent to the two identical detection axes. The lasers are focused 4 , passed through the pressure seal window 5 and into the multipass White cells 6. The power of the laser beam exiting the detection axes is monitored with a filtered photodiode 7 . The solid angle of the fluorescence collection system is roughly doubled with a retro-reflecting mirror 8 . Fluorescence (or Raman scatter) from the center $2 \mathrm{~cm}$ of the white cell is collimated' by a lens 9 and passed through one of two narrow-band interference filters held on a movable platter 10 . The light is next passed through UG-11 filter glass 11 and further filtered with a UV turning mirror 12 before being re-imaged 13 onto the masked PMT 14.

vibrational energy transfer in the excited state. (More details on energy transfer in the excited state of $\mathrm{OH}$ are given below). The thermal temperature of the $\mathrm{OH}$ in the cell is inferred to be approximately $450 \mathrm{~K}$ based on the Dopplerbroadened line shape. OH signal rates are typically 1500 counts per second (cps) on top of the laser scatter back-ground of approximately $500 \mathrm{cps}$.

It should be noted that this device is used solely for frequency reference. Its absolute $\mathrm{OH}$ sensitivity does not, in any way, enter into the calibration of the instrument.

\section{Detection axes}

A diagram of the detection axes is shown in Fig. 7. The UV beam passes out of the laser assembly (through a window in the dust and thermal enclosure) to a turning mirror. Beam movement is diagnosed with a quadrant photodetector (UDT Sensors, Hawthorne, CA), which uses the small UV leakage through the dielectric coating of this mirror. Beam movements of order $1 \mathrm{~mm}$ have been observed at this location. Movements of this magnitude have caused reduced photometric performance-"clipping" of the beam entering the White cells described below. The laser light is next divided into two beams of approximately equal energy using a hall-wave plate and polarization beam splitter (CVI Laser Optics, Albuquerque). Two Gallilean telescopes (+25 mm 
f.l./ $-25 \mathrm{~mm}$ f.l., ESCO Products, Oak Ridge, NJ) are used to focus the beams into the two identical detection axes. The use of two detection axes aides in the interpretation of the $\mathrm{HO}_{2}$ titration as well as in the diagnosis of any $\mathrm{OH}$ wall loss. To enhance the laser fluence, a (multi-pass) White cell ${ }^{36}$ is used. The laser passes through the detection volume multiple times before exiting $2 \mathrm{~cm}$ above the entrance beam. As presently configured, 32 passes are used in axis $1 ; 36$ passes in axis 2 . The exiting laser beam is then dumped into an amplified photodiode. The White-cell mirrors (Broomer Rescarch Corp., Islip, NY) arc spaced at $260 \mathrm{~mm}$ centered about the flow tube. Baffling inside the mirror-support tubes prevents fluorescence of the mirrors from entering the detection optics and dampens the cavity against acoustical resonance that could perturb the air flow. The flow tube walls surrounding the holes through which the laser beams pass are sculpted ${ }^{37}$ to prevent tripping the air-flow boundary layer .

Fluorescence and $\mathrm{N}_{2}$-Raman scatter from only the central two centimeters of the White-cell path are collected. (As discussed below, the $\mathrm{N}_{2}$ signal is used to normalize the fluorescence signal for any changes in the throughput of the entire optical train.) The extended (non-point) source is thus a sheet $2 \mathrm{~cm} \times 2 \mathrm{~cm} \times 2 \mathrm{~mm}$ (the approximate size of the sum of the laser beams at the center of the White cell). The light is imaged with a condensing lens system onto the photo-multiplier tubes (541N bialkali, EMR, Princeton, NJ). The PMTs are packaged (RSI, Hunt Valley, MD) in a single box that includes the high voltage power supply and pulse amplifier / discriminator (PAD). The observed solid angle is roughly doubled by the addition of a mirror (Newport Corp., Fountain Valley, CA) opposite the collection lens. The radius of curvature of this mirror is equal to its spacing from the center of the flow tube.

To protect the fluorescence collection optics and prevent tripping the boundary layer, anti-reflection coated windows are mounted flush with the flow tube walls. These windows are tilted a few degrees from normal incidence to shadow their surfaces from being directly illuminated by the sky. Tests using a model of the flow tube and detection axes show that this arrangement reduces the solar scatter by nearly a factor of three compared with windows placed at normal incidence. By pointing the duct opening at the blue sky, the solar scatter during flight was estimated.

The key to making high signal-to-noise $\mathrm{OH}$ measurements is providing adequate spectral filtering while maintaining high transmission of the desired wavelength. The two primary sources of noise in the experiment are laser and solar scatter. Laser light is scattered from the walls of the flow tube and directly from the air. Both of these processes produce resonant and non-resonant (red-shifted) scatter. To reduce chamber scatter, the walls throughout the duct work are specially treated with a very low fluorescence paint (Zuel, St. Paul, MN). The wall region directly around the laser and baffles is made of black-oxide coated brass. Even at the reduced air densities of the lower stratosphere, molecular scattering into the detection optics (from such processes as Rayleigh, Raman, and Mie scattering as well as broad-band fluorescence of other species) will be $10^{6}$ times the $\mathrm{OH}$ fluorescence signal. This requires very large rejection at both the laser fundamental $(282 \mathrm{~nm})$ and at the wavelength of the Stokes vibrational Raman scatter of $\mathrm{N}_{2}(302 \mathrm{~nm})$ and $\mathrm{O}_{2}$ $(295 \mathrm{~nm})$. Solar scatter is a problem because of the open nature of the sampling system and the uncertain orientation of the airplane with respect to the sun. High blocking throughout the visible and near IR is also required because the region around the detection axis can be directly (or indirectly after reflection at the walls) illuminated by the sky.

Filtering to reject scattered UV, visible, and near IR light is accomplished in four stages. After 'collimation' by an antireflection-coated, 38-mm-diameter $\mathrm{f} / 2$ lens (CVI Laser, Albuquerque, NM), the scattered light is incident on one of two narrow-band interference filters (Barr Assoc., Westford, MA) that are periodically exchanged during flight. One filter is used to observe $\mathrm{OH}$ fluorescence while the other is used to measure the Raman scatter by $\mathrm{N}_{2}$. The $\mathrm{OH}$ filter has a bandwidth (FWHM) of $4.5 \mathrm{~nm}$ centered at $310 \mathrm{~nm}$ with peak transmission of 65 percent. The $\mathrm{N}_{2}$ Raman filter has a bandwidth of $3 \mathrm{~nm}$ centered at $302.8 \mathrm{~nm}$ with peak transmission of 50 percent. A neutral density filter is added behind the $\mathrm{N}_{2}$ filter, reducing its transmission to approximately 5 percent. The center wavelengths of the filters are red-shifted by approximately $1 \mathrm{~nm}$ to account for the non-zero net angle of incidence of the ray bundle (median ray angle equal to 4 degrees). Both filters are blocked from $200-420 \mathrm{~nm}$. (Transmission $<10^{-5} \times$ peak transmission.)

The two interference filters are mounted on a pneumatically-actuated platter, allowing their interchange on command in a fraction of a second. Orifice-controlled damping in the pneumatic lines provides crisp but gentle positioning. The dry-lubricated cylinders (Bimba, Monee, Illinois) were selected for wide temperature range and low contamination potential.

Behind the filter platter, an anti-reflection coated piece of UG-11 filter glass is used to absorb visible radiation from 380 to $650 \mathrm{~nm}$; transmission in the UV is about 90 percent. Immediately following this filter, a dielectric-coated mirror (Broomer Research Corp., Islip, NY) folds the path. Visible and IR wavelengths are not reflected: transmission in the red and near IR is greater than 99 percent. Just prior to the focusing lens, the light passes through a dielectric filter to block the UG-11 red leak between 650 and $750 \mathrm{~nm}$. A focusing lens then reimages the fluorescence onto the masked PMT.

The entire filter assembly including the moving platter is enclosed in a temperature controlled $\left(20 \pm 2{ }^{\circ} \mathrm{C}\right)$ housing to prevent changes to the filter band pass or transmission. The housing is also provided with a gas purge to mitigate contamination and condensation.

Overall, this design results in very high net transmission of the $\mathrm{OH}$ fluorescence ( $T>40$ percent) with strong blocking throughout the UV, visible, and near IR. Figure 8 is a plot of the laser scatter (measured when the laser frequency is tuned to the red or blue of the $\mathrm{OH}$ transition) at the second axis for the flight of May 18, 1993. The line is a fit to the data taken in the stratosphere (pressures below $200 \mathrm{mb}$ ). Background count rates are less than $400 \mathrm{cps}$ in the stratosphere, and are dominated by laser chamber scatter. A small, but significant, pressure dependence is present. During descent into the tro- 


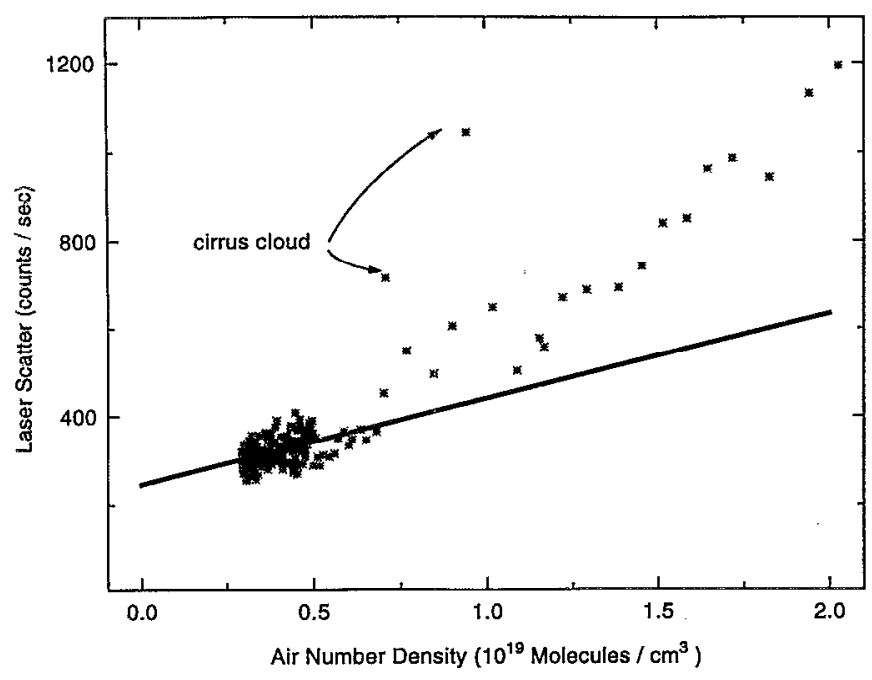

FIG. 8. Laser scatter in the detection axis. During the flight of May 18, 1993, measurements of the laser scatter were made to altitudes as low as 3 $\mathrm{km}$. The scatter (counts/sec) is plotted against number density of air. The line is a fit to stratospheric data.

posphere, other sources of scatter were observed. Scattering from a cirrus cloud is observed at $[\mathrm{M}]=7.5 \times 10^{18}$ and 9.0 $\times 10^{18}$ molecules/cc. Additionally, backgrounds continue to increase as the plane descends possibly due to fluorescence of other species, scatter from aerosols, or Raman scatter of $\mathrm{H}_{2} \mathrm{O}$ (which occurs within the bandpass of the interference filter). These signals are sufficiently small to allow measurements of $\mathrm{OH}$ fluorescence at all altitudes above the planetary boundary layer. For comparison, a concentration of one part per trillion of $\mathrm{OH}$ yields fluorescence count rates exceeding 1500 per second.

\section{E. Gas handling}

Three gas systems are used in the instrument to deliver air, nitric oxide (NO), and perfluoropropene. Air is used throughout the experiment to drive pneumatic actuators, provide purge gas to the optics and the gas addition system, and supply the $\mathrm{H}_{2} \mathrm{O}$ vapor instrument, not described here. A 2.2 liter fiberglass wound/aluminum core bottle (Structural Composites, Pomona, CA) is used at a working pressure of 3000 psi. This is regulated down to $25 \mathrm{psig}$ and is sufficient for 10 hours of operation.

Nitric oxide (CP, $99 \%$ min, Matheson, further purified by passage through an ascarite trap) is contained in a $500 \mathrm{cc}$ stainless steel bottle at pressures of up to 400 psi. This is regulated at $30 \mathrm{psig}$. Because of the extreme toxicity of nitric oxide, great care was used in the design, construction, and employment of this gas system. A spontaneously-actuated safety shut-off valve (Nupro Company, Willoughby, $\mathrm{OH}$ ), designed to operate in the case of component failure, is located just before the gas regulator. A mass-flow controller (20 sccm, MKS Instruments, Andover, MA) is used to provide variable flow rates of nitric oxide. This device was modified to incorporate thermal control and to reduce its weight by more than 50 percent. A solenoid-actuated staunching valve is located on a gas addition manifold where the nitric oxide is combined with air $(200 \mathrm{sccm})$ before being added to the ambient flow. The injector is comprised of thirteen 1.7-mm-o.d.-Teflon tubes, which cross the flow in two staggered rows. The gas is mixed into the flow through small perforations $(0.15 \mathrm{~mm})$, spaced at $5 \mathrm{~mm}$ along the tubes pointing into the flow.

Perfluoropropene $\left(\mathrm{C}_{3} \mathrm{~F}_{6}\right)$ in liquid form (vapor pressure $\approx 80 \mathrm{psi}$ at $\left.25^{\circ} \mathrm{C}\right)$ is stored in a small aluminum bottle $(150$ cc). It is added as a gas to the flow system through the gas addition manifold using a solenoid valve and a $50 \mathrm{sccm}$ stainless-steel sintered frit (Mott Metallurgical, Farmington, $\mathrm{CT}$ ). $\mathrm{C}_{3} \mathrm{~F}_{6}$ reacts with the $\mathrm{OH}$, removing it from the flow.

Command control of the low-pressure gasses throughout the instrument is achieved with low-power solenoid valves (Clippard Inst. Labs, Cincinnati, OH). Pressures in the gas handling systems are monitored with small amplified pressure transducers (Entran Devices, Fairfield, NJ).

\section{F. Data acquisition/command and control}

The data acquisition system runs under QNX (QNX, Kanata, Ontario), a realtime, multitasking, multiuser, POSIXcompliant operating system for the Intel family of microprocessors. QNX was selected in part because its simple message-passing method of inter-process communication allowed for an easy breakdown of the acquisition and control functions into a number of logically discrete processes.

Processes are divided roughly into experiment control and data acquisition. The experiment control processes are responsible for the direct manipulation of the experiment hardware: turning on and off appliances, adjusting set points, etc. The control processes can also send some basic commands to the acquisition system (start, stop, log data). Data acquisition is responsible for reading, logging, and analyzing the photometric data as well as the state of the instrument. Every process on the data acquisition side has access to the entire data stream.

Since the instrument operates in flight without direct human supervision, complex control algorithms with error recovery capability are required. For example, in order to tune the laser to the appropriate $\mathrm{OH}$ transition, data must be taken while the dye-laser frequency is being scanned. Then the data must be analyzed to determine the motor position of the peak. Such control functions that depend on the state of the instrument are implemented on the data acquisition side with all decisions made strictly on the basis of the common data stream. This makes it possible to replay an algorithm's decisions using logged data. This replay capability is crucial during algorithm development, and exceedingly useful after a flight if everything has not gone according to plan.

\section{DEPLOYMENT, OPERATION, AND CONTROL}

The core of the instrument is loaded into the aircraft nose section five hours before the projected take-off time in a process that takes approximately $45 \mathrm{~min}$. Only a portion of the experiment is routinely removable: the laser system, support electronics, power supply, gas and liquid handling systems, and detection duct comprising the core are mounted on a rack that slides into the nose. A gasket seal is made where 


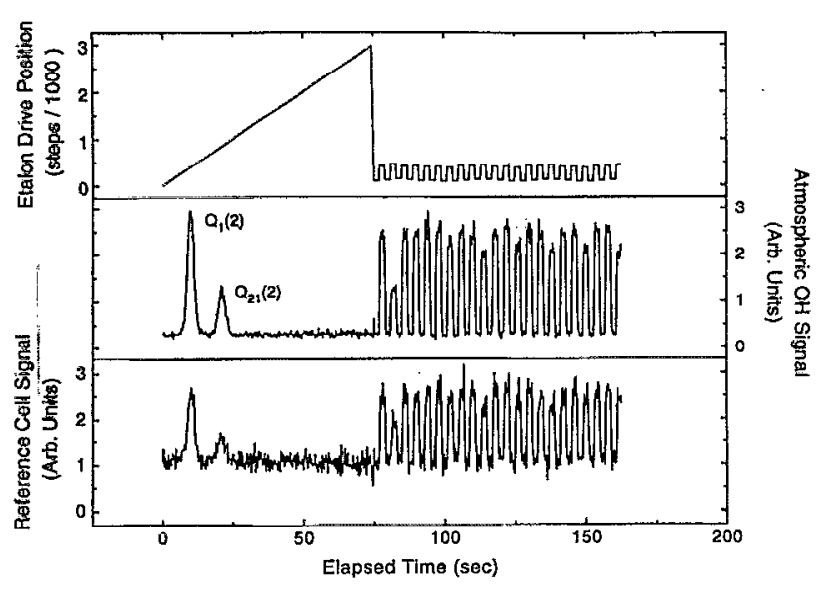

FIG. 9. OH fluorescence from the atmosphere and the $\mathrm{OH}$ reference cell during the fight of April 19, 1993. The laser frequency is scanned over the $Q_{1}(2) / Q_{21}(2)$ doublet (first $75 \mathrm{sec}$ ) and then dithered on and off resonance. The OH signal-to-noise ratio from the atmosphere (center panel) often excceds that of the frequency reference cell (bottom panel).

the forward portion of the detection duct penetrates the entrance duct and also at the detection duct connection to the outlet. The entrance duct along with the bypass duct, valves, and exhaust plenum are semi-permanently bolted into the nose section.

A one hour pre-flight check that tests all major systems is performed. Two hours before takeoff, the nose section is attached to the airframe and the loaded airplane is moved out of the hangar for fueling. For safety reasons, the valves on the nitric oxide gas system are kept closed until just before takeoff. Additionally, an arming connector is installed at that time, which enables operation of the solenoids on the gas handling system. Access for this purpose is provided through an external panel. Takeoff usually occurs within seconds of the scheduled time, with flight durations of between 2 and 8 hours.

Just prior to takeoff, the pilot turns on the experiment from an instrument panel located in the cockpit. This applies power to the computer, which begins automated turn on procedures. The laser diodes are turned on after a ten minute delay to allow for thermal stabilization of the Nd:YLF lasers and the cooling loop. After a brief warm-up period ( 3 minutes), the frequency of the dye laser is scanned, and the computer determines the location of the $\mathrm{OH}$ line center, using the signal from the frequency reference cell. The dye laser wavelength is then dithered (or chopped) by $0.5 \mathrm{~cm}^{-1}$ at $1 / 4 \mathrm{~Hz}$ to allow the background to be measured. (The slewing speed of this drive is faster than $5 \mathrm{~cm}^{-1}$ per second, which leads to very little loss of integration time during movement.) This is illustrated in Fig. 9. Signals from both the $\mathrm{OH}$ reference cell and the atmosphere are displayed as the laser frequency is first scanned and then dithered. These data were taken during the flight of April 19, 1993 at an altitude of $21 \mathrm{~km}$. The signal-to-noise ratio for ambient $\mathrm{OH}$ in the detection axes often exceeds that of the reference cell.

Environmentally-induced mechanical changes in the optical structure would result in a loss of frequency alignment over time. In order to track these changes, the on-resonance position during each chop cycle is changed slightly (about

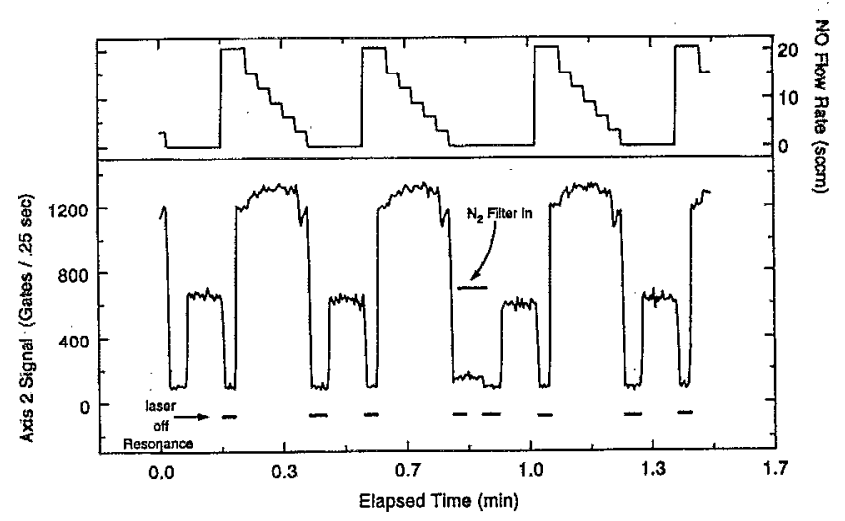

FIG. 10. Example of unaveraged $4 \mathrm{~Hz}$ data from Axis 2. Plotted as a function of time is the number of laser shots (out of a total of 1500) that yield counted fluorescence photons in any $0.25 \mathrm{sec}$ time bin. Also shown is the nitric oxide (NO) flow rate, which is used to convert $\mathrm{HO}_{2}$ to $\mathrm{OH}$. The background signals (due to laser and solar scatter) are determined by tuning the laser frequency to the blue of the $Q_{1}$ (2) absorption line (off-resonance). Overall photometric efficiency is measured periodically by observing the Stokes Raman scatter of $\mathrm{N}_{2}$ at $302 \mathrm{~nm}$.

$1 / 10$ of the $\mathrm{OH}$ line half-width). Using the signal from the frequency-reference cell, the software then determines which way to adjust the drive to track the line-center. This technique is used throughout the flight and has proven to be very robust.

The dye laser efficiency is maximized by ensuring that the peak gain occurs at the appropriate wavelength. This is accomplished by modulating the pressure in the dye laser cavity (which changes the effective refractive index of the prisms). Thermal drift and small leaks in the housing cause shifts in the gain during flight. The difference in the measured UV laser power at the two wavelengths (the on and off resonance positions) is used by the software as a feedback for adjusting the dye laser pressure. A gradient is an indication that the dye laser gain is incorrectly centered. Once a minute, the bellows is moved in the direction required to minimize the difference.

After line center attainment, $\mathrm{OH}$ and $\mathrm{HO}_{2}$ measurements are made in a $23 \mathrm{sec}$ cycle. Figure 10 shows a few cycles of data taken near local noon at $21 \mathrm{~km}$ during the flight of April 19,1993 . Plotted as a function of time is the number of laser pulses that resulted in one or more photons being detected at axis 2. During the first $3 \mathrm{sec}$, the laser frequency is offresonance and the background is measured. The laser is then tuned to the absorption peak. The laser is then once again off-resonance for $2 \mathrm{sec}$ while the NO is turned on. During the next $12 \mathrm{sec}$, the flow rate of NO is steadily decreased so that the titration of $\mathrm{HO}_{2}$ to $\mathrm{OH}$ can be observed. After every third cycle, the filter is changed and the Raman scattering is observed at both the on and off-resonant wavelengths.

Approximately every 5 minutes, the throttle valve is moved to change the velocity in the detection duct. This is used to further diagnose the kinetics of the titration of $\mathrm{HO}_{2}$, as well as to check for $\mathrm{OH}$ wall loss. After 40 minutes, the scan is repeated, and the process begins again.

Just prior to descent, the pilot pushes a switch that begins a timed shut-down. Typically, the timing is designed to 
assure that the lasers are off and the valves closed before encountering clouds in the troposphere. After landing, the data are transferred over a local area network (LAN) to the ground support computers for analysis.

Recent updates to the software will allow for automatic fault checking and correction as well as more facile data interactive control. This will allow, for instance, use of the pressure measurements to determine when to shut the instrument down during descent.

\section{DATA ANALYSIS}

\section{A. Calculation of photon arrival rates}

To achieve high signal-to-noise ratios, the photomultiplier tubes (PMTs) are operated in photon-counting mode. This serves to discriminate true photoelectrons from thermionic emission of the PMT dynodes. Due to the pulsed nature of the signal, a gated counter system can be used to reduce the background signals from cw sources (such as sunlight).

Photon counting is, however, inherently non-integrating. If two electrons are emitted by the photocathode simultaneously, or if more photons are detected during the dead time of the pulse amplifier/descriminator (PAD) or counter circuitry, only a single count is registered. Given the short fluorescence lifetime of $\mathrm{OH}$ in the lower stratosphere (5-10 ns), all signal photons will arrive during or within nanoseconds after the laser pulse. Thus, appropriate gate widths are of the order of 100 ns (the White cell travel time is approximately 40 ns). Signal rates at cruise altitude can be higher than two pulses/laser shot during $\mathrm{HO}_{2}$ measurements (and as low as 10 counts/sec for $\mathrm{OH}$ during sunset-a dynamic range of over 1000). This represents a signal rate of higher than 20 MHz. Maintaining signal linearity under these very high photon arrival rates would seem to require that the PMT/ $\mathrm{PAD} /$ counter system operate with dead times of less that 5 ns, i.e., a bandwidth of $200 \mathrm{MHz}$. While this is certainly not beyond what is feasible, it is technically challenging and would further preclude the use of the RSI PAD package, which has a long history of successful use in our research group.

To circumvent the linearity problem a novel gated counter system was devised. Surprisingly, by reducing the bandwidth of the system it is possible to accurately infer the true signal arrival rates. By ensuring that at most one count can be registered per laser shot, we can exploit Poisson statistics to calculate the true photoelectron arrival rate. Consider $M$ gates with $N$ photoelectrons. Then, $\mu=N / M$ is the mean number of photoelectrons per gate. Assuming a Poisson distribution, the probability that $x$ photoelectrons will arrive in a given gate is given by:

$$
\frac{\mu^{x}}{x !} \times e^{-\mu} \text {. }
$$

The probability that zero photoelectrons will be detected in any gate is then equal to $e^{-\mu}$. So, the probability that one or more photoelectrons will be detected is just $1-e^{-\mu}$. Finally, the expectation for the number of gates with detected photoelectrons (the observable) is $G=M \times\left[1-e^{-N / M}\right]$. Solving for $N$ we find:

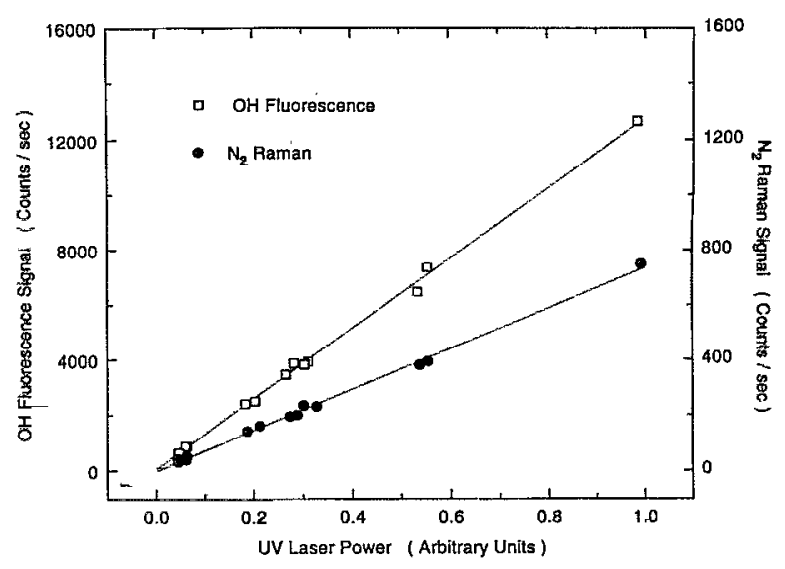

FIG. 11. Undercounting correction. Inferred photoelectron arrival rate (counts/sec) vs laser power (arbitrary units). The gated counter is designed to register at most one event per laser shot. Poisson statistics are employed to infer the true photoelectron arrival rate. Data taken during the flight of April 19, 1993 show that the counting system remains linear to count rates exceeding two times the laser repetition rate.

$$
N=-M \ln \left(1-\frac{G}{M}\right)
$$

Using this expression to infer $\mathrm{N}$ from $\mathrm{G}$, it is possible to maintain linearity to extremely high count rates. In the laboratory, Eq. (9) has been demonstrated to provide linearity to count rates in excess of four times the pulse repetition rate. Flight data also demonstrate this capability. Shown in Fig. 11 are data from the flight of April 19, 1993. To check for signal linearity, the UV power of the laser system was modulated from 0 to 100 percent ( 1 unit is approximately $5 \mathrm{~mW}$ of laser light into each detection axis). These data were taken while NO was being added to achieve maximum $\mathrm{OH}$ concentrations in the detection volume. As can be seen, linearity is being maintained to count rates in excess of two 'counts' per laser shot.

\section{B. Calculation of the laser-power-normalized signal}

Signal due to solar scatter is removed from the data by subtracting a count rate equal to the duty cycle of the gate, in this case $4 \times 10^{-4}$, times the difference of the ungated and gated signals. Sunlight infiltration gives rise to count rates of between 10 and 50 thousand per second in the ungated 309$\mathrm{nm}$-filtered channel, and 100 to 1000 in the $302-\mathrm{nm}$ channel. A marked reduction in this signal was observed between flights in the fall of 1992 and flights in the spring of 1993, apparently because of the reduction in atmospheric aerosol loading as the Pinatubo volcanic cloud settled out of the lower stratosphere.

After removing the solar signature, the signal rates are normalized to laser power. Typically, the power monitor located just after the dye laser is used for this normalization, but provided that the same monitor is used for both the 309-nm channel and the 302-nm channel, either this monitor or the detector after the White cell can be used. The signal due to $\mathrm{OH}$ fluorescence is then determined by subtracting the laser-scatter background (determined with the laser otfresonance) from the on-resonance signal. Both the on- and 
off-resonant signals from the $\mathrm{N}_{2}$ Raman signal are used to define the calibration as discussed below. The difference is also calculated to check for bias in the scatter for the two laser wavelengths.

\section{Calculation of the concentration of $\mathrm{OH}$}

'To convert the retrieved fluorescence signals to absolute $\mathrm{OH}$ densities requires a combination of laboratory and inflight calibration. Equation (10) is the fundamental relation that governs this conversion.

$$
\text { OH Signal }=[\mathrm{OH}] \times E \times Q \times C
$$

$$
E \text { (Excitation Rate) } \propto \frac{N_{N^{\prime \prime}=2}}{N} \times \mathscr{F}_{\text {laser }} \int_{-\infty}^{\infty} \phi_{\nu(\text { laser })} \sigma_{\nu} d \nu,
$$

where:

$\frac{N_{N=2 "}}{N} \equiv$ The normalized OH population density

in the probed rotational state

$$
\left(v^{\prime \prime}=0, N^{\prime \prime}=2, j^{\prime \prime}=5 / 2\right),
$$

$\mathscr{F}_{\text {laser }}=$ The average laser power circulating

in the white cells,

$\int_{-\infty}^{\infty} \phi_{\nu \text { (laser) }} \sigma_{\nu} d \nu \equiv$ The effective $\mathrm{OH}$ absorption

cross section,

$\phi_{\nu(\text { laser })}$ 亚The normalized laser frequency lineshape,

$\sigma_{p} \equiv$ the $\mathrm{OH}$ absorption cross section,

$Q$ (fluorescence efficiency) $\equiv$ fraction of excited $\mathrm{OH}$ that

$$
\text { fluoresce from } v^{\prime}=0 \text {, }
$$

$C$ (collection efficiency) $\propto A \times \Omega \times \tau \times \eta$,

$A \times \Omega=$ Area solid angle product of the

collection optics,

$\tau=$ Transmission of the fluorescence collection optics,

$\eta \equiv \mathrm{PMT}-\mathrm{PAD}$ quantum efficiency.

The. optical throughput of the system, $\mathscr{F}_{\text {laser }} \times A \times \Omega \times \tau \times \eta$, is monitored during flight by exchanging the narrow band $\mathrm{OH}$ filter centered at $310 \mathrm{~nm}$ with a filter centered at $302 \mathrm{~nm}$ where Raman scatter of the laser by $\mathrm{N}_{2}\left(2331 \mathrm{~cm}^{-1}\right)$ is observed. Provided the relative transmission of the $\mathrm{OH}$ and $\mathrm{N}_{2}$ filters is constant, this serves to normalize for any change in the PMT or the throughput of the fluorescence (or laser) optics. As discussed in detail below, calibration in the laboratory is used to relate the sensitivity to $\mathrm{OH}$ to the sensitivity to $\mathrm{N}_{2}$. In-flight measurement of pressure and temperature allows accurate measurement of the sensitivity as a function of timc and by inference the time-dependent $\mathrm{OH}$ sensitivity. The utility of this normalization method was demonstrated during the spring 1993
SPADE (Stratospheric Photochemistry, Aerosol, and Dynamics Expedition) campaign. On some flights environmental effects caused changes in the laser beam pointing direction. These changes affected the two $\mathrm{OH}$ detection axes very differently. The relative $\mathrm{N}_{2}$ sensitivity of the two axes changed by as much as 35 percent. After normalization by the $\mathrm{N}_{2}$ sensitivity, however, the retrieved $\mathrm{OH}$ mixing ratios for the two axes were identical ( \pm 5 percent).

The other variables in Eq. (10) depend, in general, on the ambient pressure and temperature. The changes in these terms between the laboratory calibration and flight conditions are calculated as described below.

\section{1. $N_{N^{\prime \prime}=2} / N$ : The normalized population density in the $N^{\prime \prime}=2$ rotational level}

Because the laser excites $\mathrm{OH}$ from a single rotational level, the signal will be proportional to the concentration of $\mathrm{OH}$ in that level. In this experiment the $Q_{1}(2)$ transition is probed. Thus we need to determine the normalized population density in the $N^{\prime \prime}=2$ rotational level of the ${ }^{2} \Pi_{3 / 2}$ electronic state. This is directly calculated from the spectroscopic constants $^{38}$ and the observed temperature. At the typical temperature of the measurements, $235 \mathrm{~K}, N_{N^{\prime \prime}=2} / N=0.11$. (We assume that the $\mathrm{OH}$ is in thermal equilibrium at the measured flow temperature.)

\section{2. $\int_{-\infty}^{\infty} \phi_{\nu(\text { laser })} \sigma_{\nu} d \nu:$ The laser power normalized excitation rate}

The net excitation rate is a detailed function of the frequency $(\nu)$ and frequency width $(\Delta \nu)$ of the laser and the pressure and temperature dependent line shape of the $\mathrm{OH}$ absorption feature. To accurately retrieve $\mathrm{OH}$ densities, the data must be corrected to account for changes in these terms from the laboratory to flight.

The laser frequency distribution, $\phi_{\nu \text { (laser) }}$, is well described by a Gaussian of width $0.098 \pm 0.010 \mathrm{~cm}^{-1}$. The width is monitored evcry $1 / 2$ hour during flight with the high finesse etalon as described above. The integrated $\mathrm{OH}$ absorption cross section is, of course, directly proportional to the oscillator strength of the transition. At the pressure altitudes of these measurements, the $\mathrm{OH}$ transition line shape is broadened by both homogeneous (pressure broadening) and inhomogeneous (Doppler broadening) processes. The appropriate line shape is thus a mixed Doppler/Lorentzian known as the Voigt profile, which cannot be evaluated in closed form. An approximation to this line shape by Whiting ${ }^{39}$ has been shown to accurately describe the $\mathrm{OH}$ pressure broadening. ${ }^{40}$ Using literature data for the pressure broadening at room temperature ${ }^{40}$ and the temperature dependence, ${ }^{41}$ a model of the line shape is constructed. (Lorentz width at half-height $=26.4 \times 10^{-5} x P\{296 / T\}^{0.8} ; P$ in torr; $T$ in K). Figure 12 shows three scans of the $Q_{1}(2), Q_{21}(2)$ doublet $\left(\tilde{A}^{2} \Sigma^{\prime}\left(v^{\prime}=1\right) \leftarrow \tilde{X}^{2} \Pi_{3 / 2}\left(v^{\prime \prime}=0\right)\right)$. Figure $12(\mathrm{C})$ is a scan taken in the laboratory at room temperature in a low pressure flow tube ( 5 torr $\mathrm{N}_{2}$ ) where the line shape is essentially Doppler broadened. Scan 12(B) was taken near the ER-2 cruise altitude $(19 \mathrm{~km})$. Scan 12(A) was taken during 


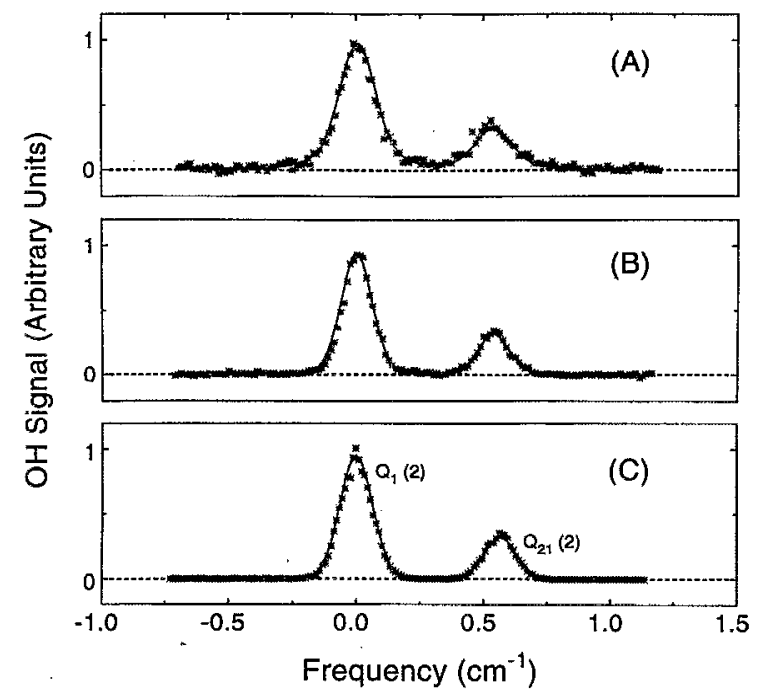

FIG. 12. Pressure broadening of the $\mathrm{OH}$ transition. (A) is data from $8 \mathrm{~km}$ during the fight of May 3, 1993. (B) is data from $18 \mathrm{~km}$ during the same flight. (C) is a scan taken in the laboratory at total pressure of 5 torr (no pressure broadening). Pressure broadening is apparent in the atmospheric data and is well described by a Whiting line shape (line).

ascent at $8 \mathrm{~km}$. The line is the model whose only input is the relative height ${ }^{42}$ and separation ${ }^{43}$ of the $Q_{1}(2)$ and $Q_{21}(2)$ peaks, the temperature, and the pressure. Homogeneous broadening is easily discernible in these scans-the wings of the lines fill in as the pressure increases. The net effect of pressure broadening is to reduce the sensitivity of the instrument by approximalely 15 percent at ER-2 cruise altitudes and by as much as 35 percent at $15 \mathrm{~km}$ over what would be expected for pure inhomogeneous broadening.

As described above, the laser frequency is 'locked' onto the $\mathrm{OH}$ line by dithering the frequency about the line center. While this serves to prevent gross loss of frequency alignment, it injects one-sided "noise" into the retrieved OH concentrations due to the reduction in the excitation rate. Assuming that the dithering is not biased to either side of line center, we cari apply a low pass filter to the etalon drive position and determine an estimate of the true line center as a function of time. This then allows us to infer the degree of detuning of the laser during each measurement cycle. Figure 13 shows the drive position as a function of time for the flight of May 3, 1993. Also shown is the filtered retrieval of the true line-center position. Using the model of the absorption line shape, the signals can be corrected for the detuning from line center. Figures 14(a) and 14(b) show the result of correcting for frequency mismatch. In Fig. 14(a), the signal at axis 1 divided by a 10 point running median is plotted against the calculated detuning. Figure 14(b) shows the result of correcting the data; no bias is apparent.

\section{3. $Q$ : The fluorescence efficiency}

The fraction of hydroxyl radicals excited to the $v^{\prime}=1$ vibrational level of the ${ }^{2} \Sigma$ state that fluoresce in the $\mathrm{v}^{\prime}=0$ band is the dimensionless fluorescence efficiency, $Q$. The

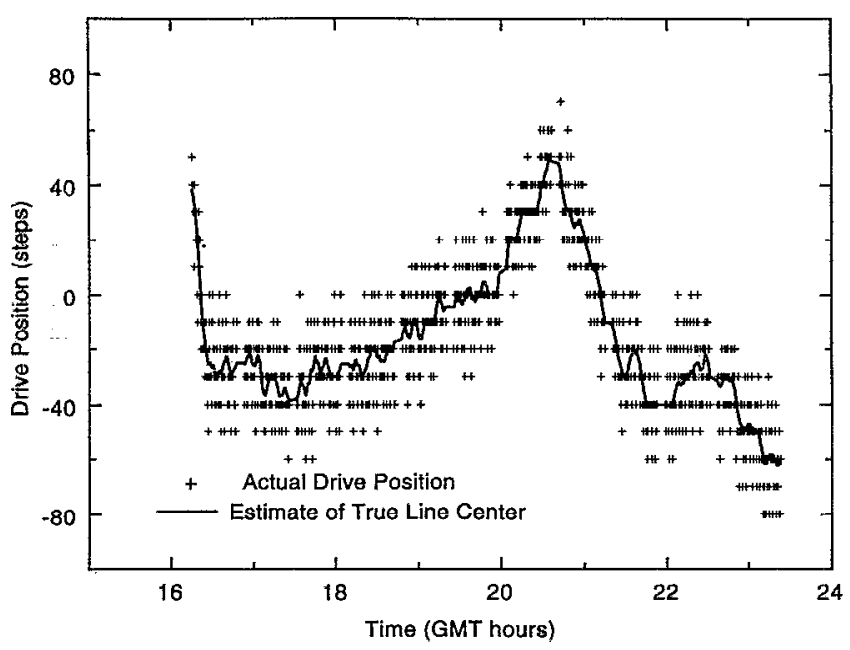

FIG. 13. The dye laser tuning position (steps) vs time on the flight of May 3, 1993: * $\equiv$ actual position; solid line $\equiv$ filtered estimate of the line center. See the text for details.

value of $Q$ is calculated from laboratory measurements of the rate constants for fluorescence and energy transfer in the excited state:

$Q=$ Fraction of $\mathrm{OH}^{2} \Sigma\left(v^{\prime}=1\right)$ that transfer to $v^{\prime}=0$ $\times$ Fraction of $\mathrm{OH}^{2} \Sigma\left(v^{\prime}=0\right)$ that fluoresce,

$Q=\frac{k^{v-v}[M]}{k_{v^{\prime}=1}^{\mathrm{rad}}+k^{v-v}[M]+k_{v^{\prime}=1}^{Q}[M]} \times \frac{k_{v^{\prime}=0}^{\mathrm{rad}}}{k_{v^{\prime}=0}^{\mathrm{rad}}+k_{v^{\prime}=0}^{Q}[M]}$,

where:

$k^{v-v} \equiv$ Vibration Energy Quenching Rate-

$$
\left(\mathrm{cm}^{3} \text { molecules }{ }^{-1} \mathrm{scc}^{-1}\right) \text {, }
$$

$[M] \equiv$ Molecular Number Density-(molecules $\mathrm{cm}^{-3}$ ),

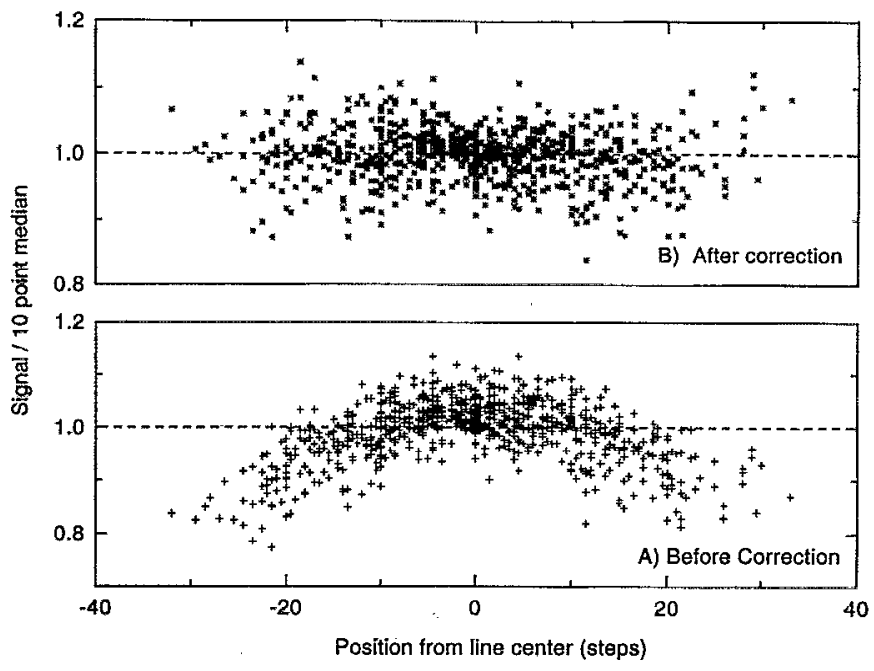

FIG. 14. Effect of laser detuning on signal rates. (A) Signal /10 point median as a function of the detuning (steps) inferred above [One step $\mid \approx 0.0013$ $\mathrm{cm}^{-1}$ ]. (B) Same data after correction described in the text. 
$k^{Q} \equiv$ Electronic Energy Quenching Rate--

$\left(\mathrm{cm}^{3}\right.$ molecules $\left.{ }^{-1} \mathrm{sec}^{-1}\right)$,

$k^{\text {rad }} \equiv$ Fluorescence Rate

$$
=\frac{1}{\text { Fluorescence Lifetime }}-\left(\sec ^{-1}\right) \text {. }
$$

Table I gives the values of the constants used to evaluate $Q$. These are culled from the literature ${ }^{44-51}$ and from unpublished results of our laboratory and the laboratory at SRI. ${ }^{52}$ Confidence in this parameterization of the fluorescence efficiency, at least at room temperature, comes from calibration studies in the laboratory as discussed below. The temperature dependence, which is fairly weak, will be the subject of laboratory study in the near future. Above 10 torr, the fluorescence lifetime is dominated by electronic quenching. As a result, $Q$ is almost inversely proportional to $[M]$ and thus signal rates are approximately linear in $\mathrm{OH}$ mixing ratio. At ER-2 cruise altitude only one percent of the absorption results in fluorescence.

\section{Laboratory calibration}

In the laboratory, the absolute $\mathrm{OH}$ sensitivity of each detection axis is measured relative to the sensitivity for $\mathrm{N}_{2}$ Raman scattering by producing a known concentration of hydroxyl radicals in a low-pressure flow tube. $\mathrm{OH}$ is generated by titration of known concentrations of $\mathrm{NO}_{2}$ in excess $\mathrm{H}$-atoms $\left[\mathrm{k}=1.3 \times 10^{-10} \mathrm{~cm}^{3}\right.$ molecules ${ }^{-1} \mathrm{sec}^{-1}$ (Ref. 53)]:

$$
\mathrm{NO}_{2}+\mathrm{H} \rightarrow \mathrm{OH}+\mathrm{NO} \text {. }
$$

$\mathrm{H}$ atoms are produced by dissociation of molecular hydrogen in a He plasma generated in a high-pressure microwave cavity. ${ }^{54}$ The hydrogen atoms are added to the flow through a movable injector such that variable concentrations of $\mathrm{H}$ atoms $\left(0.1-3.0 \times 10^{12} \mathrm{~cm}^{-3}\right)$ can be produced. By moving the position of the $\mathrm{H}$-atom injection the reaction time can be varied. This procedure allows for diagnoses of wall loss of $\mathrm{OH}$ as well as tests for any secondary chemistry. Under ideal conditions (no secondary chemistry or wall loss), the concentration of $\mathrm{OH}$ produced will equal the initial concentration of $\mathrm{NO}_{2}$. The $\mathrm{OH}$ formed in reaction (12) is known to be produced rotationally and vibrationally "hot." Fully 50 percent of the nascent $\mathrm{OH}$ is vibrationally excited. ${ }^{55}$ While the large number density of $\mathrm{N}_{2}$ in the flow tube will effectively quench the rotational energy, vibrational energy quenching by $\mathrm{N}_{2}$ is known to be very inefficient (in the ground electron state). Fortunately, non-reactive vibrational quenching of $\mathrm{OH}$ by $\mathrm{H}$ atoms occurs at a rate comparable to the rate of reaction (12). ${ }^{56}$

$\mathrm{NO}_{2}$ [20.7 ppm in $\mathrm{N}_{2}$ (Scott)] is premixed into the bulk flow (20-200 standard liters per minute, $\mathrm{N}_{2}$ ), producing concentrations of $1-1000 \times 10^{8} \mathrm{~mol} / \mathrm{cc}$ of $\mathrm{OH}$ at pressures between 1 and 50 torr. The concentration of $\mathrm{NO}_{2}$ in the cylinder is compared against accurately known standards prepared in the laboratory with pure $\mathrm{NO}_{2}>99.5$ percent, Matheson, purified by vacuum distillation) and ultra high purity $\mathrm{N}_{2}$.

\begin{tabular}{|c|c|}
\hline Process & $\mathrm{k}\left(\mathrm{cm}^{3}\right.$ molecule $\left.{ }^{-1} \mathrm{sec}^{-1}\right)$ \\
\hline $\begin{array}{c}k^{v-v} \quad v^{\prime}=1 \rightarrow v^{\prime}=0 \text { transfer } \\
\text { in the } A^{2} \Sigma \text { state }\end{array}$ & $\begin{array}{l}2.3 \times 10^{-10}\left(\mathrm{~N}_{2}\right) \\
3.5 \times 10^{-11}\left(\mathrm{O}_{2}\right)\end{array}$ \\
\hline $\begin{array}{c}k_{v^{\prime}=1}^{Q}: \text { Electronic quenching } \\
A^{2} \Sigma\left(v^{\prime}=1\right)\end{array}$ & $\begin{array}{c}1.6 \times 10^{-10}\left(\mathrm{O}_{2}\right) \\
7.3 \times 10^{-12} \exp \left(\frac{379}{T}\right)\left(\mathrm{N}_{2}\right)\end{array}$ \\
\hline $\begin{array}{c}k_{v^{\prime}=0}^{Q}: \text { Electronic quenching } \\
A^{2} \Sigma\left(v^{\prime}=0\right)\end{array}$ & $\begin{array}{c}1.4 \times 10^{-10}\left(\mathrm{O}_{2}\right) \\
7.3 \times 10^{-12} \exp \left(\frac{379}{T}\right)\left(\mathrm{N}_{2}\right)\end{array}$ \\
\hline $\begin{array}{l}k^{\text {rad }}: \text { Radiafive rate } \\
\qquad A^{2} \Sigma\left(v^{\prime}=0,1\right)\end{array}$ & $1.44 \times 10^{6} \sec ^{-1}$ \\
\hline
\end{tabular}

TABLE I. Rate data used to calculate $Q$, the fluorescence efficiency.

The efficacy of the titration has been tested by means of direct UV absorption. A $50 \mathrm{~cm}$ base path length White cell is used to measure the concentration of $\mathrm{OH}$ in the same volume element that the LIF is performed. An optical fiber feeds a fraction of the laser into the multipass cell that straddles the detection axes. A beam splitter samples the collimated light before it is focused into the cell as a normalization technique. Both this light and the light exiting the White cell after approximately 10 meters path length are monitored with vacuum phototubes (R765, Hamamatsu, Bridgewater, NJ). The calibration of the detection axes using this technique agrees to within 10 percent with the titration method.

The laser is heavily attenuated during these calibrations in order to keep signal rates below $10,000 \mathrm{cps}$. A combination of the built-in attenuator and a glass microscope slide is used to reduce the laser power by $1-10$ thousand. This heavy attenuation made simultaneous measurements of the $\mathrm{OH}$ and $\mathrm{N}_{2}$ Raman sensitivities impossible. Usually, determination of the Raman sensitivity was made only at the beginning and end of each calibration run (approximately 4 hours). This, unfortunately, presented a significant source of imprecision.

After accounting for changes in the fluorescence efficiency, the calibration is independent of pressure. This gives further corroboration to the parameterization of the fluorescence efficiency described above. Additional experiments were performed to investigate the effect of oxygen on the calibration. A thermal source was used to prepare a small concentration of $\mathrm{OH}$ in air. The $\mathrm{OH}$ produced was then mixed into the bulk flow producing $\mathrm{OH}$ concentrations of order $10^{4}$ molecules/cc. The signal was measured as the composition of the bulk flow was changed from 0 to 25 percent $\mathrm{O}_{2}$. The modeled-fluorescence efficiency described the data extremely well ( \pm 10 percent) for all pressures between 5 and 30 torr-confirming the expected decrement in sensitivity in air vs $\mathrm{N}_{2}$. The fluorescence lifetime in air is reduced to less than half of what it is in $\mathrm{N}_{2}$ because of the much more efficient quenching of $\mathrm{O}_{2}$. Studies of the tem- 
perature dependence of the calibration have not yet been performed.

The calibration factors, $C_{\mathrm{OH}} / C_{\mathrm{N}_{2}}$, should be equal to the ratio of the effective cross-sections for absorption and Raman scattering modified by the difference in the net collection efficiency at the two wavelengths $\left(T_{\mathrm{OH}} / T_{\mathrm{N}_{2}}\right)$. The Raman back scattering cross-section of $\mathrm{N}_{2}$ at $282 \mathrm{~nm}, \sigma_{\mathrm{N}_{2}}$, is $7.6 \pm 0.8 \times 10^{-30} \mathrm{~cm}^{2} \mathrm{sr}^{-1}$ for the sum of the $O, Q$, and $S$ branches of the Stokes transitions. ${ }^{57}$ To minimize Rayleigh and Raman scatter in the $\mathrm{OH}$ channel, the laser polarization is rotated to the minimum of the Rayleigh lobe. The ratio of the scatter at this polarization compared with the backscatter condition has been measured by rotating the polarization 90 degrees. At axis two the depolarization, $\rho$, was measured to be $5.4 \pm 0.5$, while at axis one it was measured to be 3.3 \pm 0.5 . The difference is due to a small amount of leakage of the "wrong" polarization plane into axis one through the beam splitter. At low pressure, for the $Q_{1}(2) \mathrm{OH}$ transition, the average absorption cross-section (integrated across the $0.098 \mathrm{~cm}^{-1}$ laser frequency width), $\sigma_{\mathrm{OH}}$, is $9.2 \pm 1.0$ $\times 10^{-18} \mathrm{~cm}^{2} \mathrm{sr}^{-1}$ at room temperature. ${ }^{42.58}$ Thus, we expect:

$$
\begin{aligned}
\frac{C_{\mathrm{OH}}}{C_{\mathrm{N}_{2}}} & =\frac{\sigma_{\mathrm{OH}}}{\sigma_{\mathrm{N}_{2}} / \rho} \times \frac{T_{\mathrm{OH}}}{T_{\mathrm{N}_{2}}} \\
& =6.7 \pm 1.0 \times 10^{12} \times \frac{T_{\mathrm{OH}}}{T_{\mathrm{N}_{2}}}(\text { Axis 2) } \\
& =4.1 \pm 0.8 \times 10^{12} \times \frac{T_{\mathrm{OH}}}{T_{\mathrm{N}_{2}}}(\text { Axis } 1) .
\end{aligned}
$$

Our calibration of the detection axes yields (for $Q=1$ ):

$$
\begin{aligned}
\frac{C_{\mathrm{OH}}}{C_{\mathrm{N}_{2}}} & =1.9 \pm 0.3 \times 10^{14} \text { (Axis 2) } \\
& \left.=1.3 \pm 0.2 \times 10^{14} \text { (Axis } 1\right) .
\end{aligned}
$$

From this we estimate:

$$
\begin{aligned}
\frac{T_{\mathrm{OH}}}{T_{\mathrm{N}_{2}}} & =29 \pm 5 \quad(\text { Axis 2) } \\
& =32 \pm 6(\text { Axis } 1) .
\end{aligned}
$$

The net photometric efficiency of the detection system at the two wavelengths is difficult to measure as it involves a detailed integral of the transmission over the spectral distribution of both the $\mathrm{OH}$ rotational manifold and the $\mathrm{N}_{2} \mathrm{O}, Q$, and $S$ branches. This in turn depends on the angle of incidence on the interference filters. To first order, however, the transmissions can be estimated by averaging the transmission of the filters near the source: $\mathrm{T}_{\mathrm{OH}} \approx T_{307-312 \mathrm{~nm}}, \mathrm{TN} 2$ $\approx T_{302 \mathrm{~nm}}$. These were obtained on a spectrophotometer of $2.5 \AA$ resolution (and divergence nearly identical to the flight detection axes):

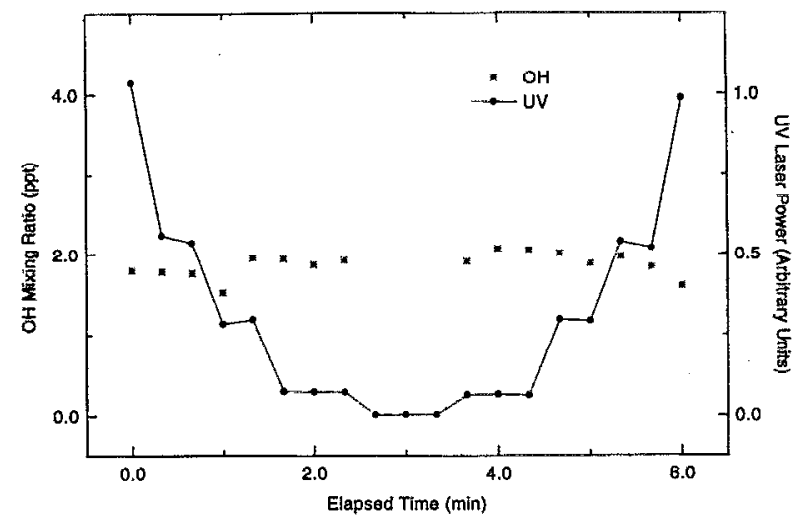

FIG. 15. Shown are ten minutes of $\mathrm{OH}$ measurements from the flight of April 23, 1993 during a period when the laser power was modulated. The retrieved $\mathrm{OH}$ densities show no tendency with laser power. This would not be the case if a sizable fraction of the signal were due to production of $\mathrm{OH}$. by the laser.

$$
\begin{aligned}
\frac{T_{\mathrm{OH}}}{T_{\mathrm{N}_{2}}} & =32 \text { (Axis 2) } \\
& =33 \text { (Axis 1). }
\end{aligned}
$$

The laboratory measurements of the $\mathrm{OH}$ and $\mathrm{N}_{2}$ sensitivities and optical transmission yield a ratio of the cross section of $\mathrm{OH}$ to $\mathrm{N}_{2}$ within 10 percent of the expected value -well within the uncertainties both in the absolute $\mathrm{OH}$ calibration and the calculation of the net transmission.

\section{E. Photochemical interference}

As discussed above, the laser-induced-fluorescence technique suffers from potential photochemical interferences. Using the built in diagnostics, flight experience demonstrates that in the stratosphere the instrument is free of such prob. lems. Three different techniques were used to diagnose any' difficulties.

\section{Laser power modulation}

Shown in Fig. 15 are data taken during the flight of April 23, 1993. OH measurements are being made as the laser power is modulated from 100 percent to 10 percent. The retrieved $\mathrm{OH}$ densities show no trend with laser power. This would not be the case if a sizable fraction of the signal were due to $\mathrm{OH}$ generated by the laser as described above.

\section{Chemical modulation}

Chemical removal of the ambient $\mathrm{OH}$ is a completely different approach to measuring the laser background signal. Unlike the spectral modulation discussed above, chemical modulation should yield a background measurement that includes the contribution due to photochemical production of $\mathrm{OH}$ during the laser pulse, which in the nanosecond time scale will not be affected by the small concentration of chemical. Perfluoropropene $\left(\mathrm{C}_{3} \mathrm{~F}_{6}\right)$ was chosen as the chemical modulator for a number of reasons.

$\mathrm{OH}$ reacts with haloalkenes by adduct formation, ${ }^{59}$ and so does not lead to further radical chemistry on the time scales of interest here. Stabilization of the adduct is so effi- 
cient that the high pressure limit is reached at pressures below 75 torr. $^{60}$ Using the discharge flow technique, we have measured the rate constant for the addition reaction to be $(6.0$ $\pm 1.0) \times 10^{-13} \exp \left[(370+40) / T \mathrm{~cm}^{3}\right.$ molecules $\left.{ }^{-1} \mathrm{sec}^{-1}\right]$, over the temperature range $240-300 \mathrm{~K}$. Details of this study are described by Dubey et al. ${ }^{61}$ This is in excellent agreement with the recently published higher-temperature results of McIlroy and Tully. ${ }^{60}$ Unlike hydrocarbons that have been used by others for this purpose, ${ }^{62} \mathrm{O}\left({ }^{1} D\right)$ produced in the laser beam will not react with perfluoropropene to produce OH. Physical properties of $\mathrm{C}_{3} \mathrm{~F}_{6}$ also make it ideal for this use. It is not toxic or flammable (this is surprising in light of the nearly explosive properties of analogous compounds; tetrafluoreoethylene, for example, polymerizes explosively). Because $\mathrm{C}_{3} \mathrm{~F}_{6}$ is a liquid with a modest vapor pressure, a small lightweight bottle can be employed.

During the flights of November 16 and 20, 1992, the chemical modulation technique was employed. Complete suppression of the signal was demonstrated-showing that all the OH signal was from ambient hydroxyl. This method of background measurement should be very useful if $\mathrm{OH}$ measurements are attempted in the troposphere where some photochemical interference is expected because of the large mixing ratios of $\mathrm{H}_{2} \mathrm{O}$.

\section{Night time data}

Data at very high solar zenith angles $($ SZA $>110)$ provide an alternative method for determination of an upper limit to the interferences. Generation of $\mathrm{OH}$ by the laser should not depend on the SZA provided that the species involved in laser production of $\mathrm{OH}$ do not exhibit diurnal dependencies. This is certainly true of $\mathrm{O}_{3}, \mathrm{H}_{2} \mathrm{O}$, nitric and pernitric acid, and formaldehyde, it is not true of HONO. Nevertheless, it is expected that the source due to $\mathrm{O}_{3} /$ $\mathrm{H}_{2} \mathrm{O}$ will dominate.

Portions of six flights in the fall of 1992 and the spring of 1993 took place during the night. Retrieved $\mathrm{OH}$ densities were less than $0.01 \mathrm{ppt}$ for SZA $>110$. The statistically significant positive residuals were found, however, to be independent of laser power. During the flight of May 11, 1993, it was discovered that modulating the frequency to the blue of the $\mathrm{OH}$ transition, resulted in negative signal residuals of nearly equal magnitude. It seems that either there is broadband fluorescence from another species, or more likely, the chamber scatter is changing slightly during frequency modulation. This could easily result from the small beam pointing direction change that occurs when the laser wavelength is dithered.

In conclusion, there is no evidence that $\mathrm{OH}$ is made and detected by this experiment during stratospheric observations. An upper limit for this interference of 0.005 parts per trillion is estimated from the available diagnostic data. It should be noted that this determination has been only made in the lower stratosphere where $\mathrm{O}_{3}$ and $\mathrm{H}_{2} \mathrm{O}$ mixing ratios are typically 2 and 4 parts per million, respectively.

\section{F. Uncertainty in calculated $\mathrm{OH}$ mixing ratios}

Error in the determination of the $\mathrm{OH}$ density can be broken down into two components: uncertainty in the laboratory calibration in the ratio of the sensitivity of the instrument for $\mathrm{N}_{2}$ scatter vs $\mathrm{OH}$ fluorescence; and uncertainty in the inference of the $\mathrm{OH}$ sensitivity in flight. As discussed above, the laboratory calibration, at present, is uncertain to approximately 20 percent.

The changes in the $\mathrm{OH}$ excitation rate between the laboratory and flight conditions should not be a source of significant error. The parameterization of the line shape has been demonstrated to fit the observed excitation spectra for all pressures. In any case, over most of the altitude region where measurements are made, the change in excitation rate due to line shape is small. The calculation of the population density in the appropriate rotation level should be exact. The use of the Raman signal has been demonstrated to effectively measure changes in the optical performance.

Although the parameterization of the fluorescence efficiency has been shown in the laboratory to fit the observed pressure and gas composition dependence of the sensitivity, no calibrations have been done yet at lower temperatures. Only one study of the temperature dependence of the electronic quenching rates has been reported. ${ }^{49}$ This measurement implies a reduction of the fluorescence efficiency from that at room temperature of approximately 20 percent at the average temperatures during measurement $(230 \mathrm{~K})$. This study was performed in a manner, however, that ensured that the rotational distribution in the excited state was thermalized. Although rotational energy transfer is known to be very efficient, ${ }^{63,64}$ it is not known at the present to what extent thermalization of the rotational levels in the excited state occurs after the vibrational energy transfer (which produces a rotationally-excited distribution ${ }^{51,52}$ ). As it is known that lower rotational states are more efficiently quenched, ${ }^{65,48}$ the temperature dependence from Copeland et al. ${ }^{49}$ is likely to be an upper limit for these conditions.

The net uncertainty is thus about 30 percent $(2 \sigma)$. The precision of the data set is, however, much higher. This is very useful in, for instance, examining the gradients of $\mathrm{OH}$ and $\mathrm{HO}_{2}$ with other chemical and meteorological data sets available from the instruments aboard the aircraft.

\section{G. Calculation of the concentration of $\mathrm{HO}_{2}$}

As described above, $\mathrm{HO}_{2}$ measurements are performed by additions of nitric oxide into the flow. During each cycle typically seven different mass flow rates of NO are added. For each flow, the $\mathrm{OH}$ density is extracted just as described above. A non-linear least-squares fit to a kinetic model using reactions (5) and (6) is then used to infer the $\mathrm{HO}_{2}$ concentration. $\mathrm{HO}_{2}$ concentrations are determined in this manner for each axis, and in a single fit of the data from both axes, which yields results that are usually within 5 percent of each other. An example of the titration curve is shown in Figure 16. The $\mathrm{OH}$ density is plotted as a function of the product of the NO density, the reaction time, and the rate constant for reaction (5). Two anomalies are apparent. The peak $\mathrm{OH}$ densities occur at a concentration of NO 30 to 80 percent lower 


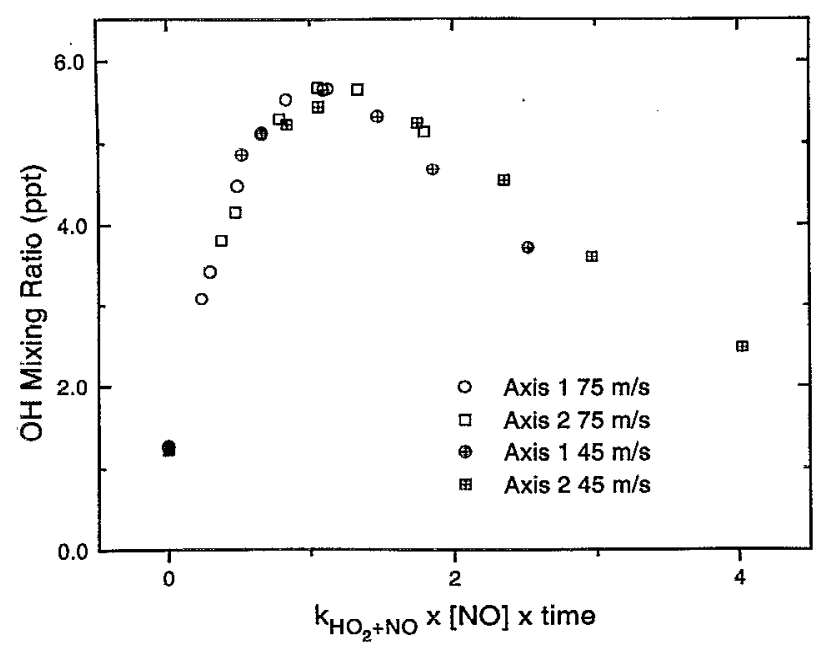

FIG. 16. In flight titration of $\mathrm{HO}_{2}$ to $\mathrm{OH}$. The $\mathrm{OH}$ mixing ratio is plotted as a function of the product of the NO density, the reaction time, and the rate constant for the production of $\mathrm{OH}$ from $\mathrm{HO}_{2}$. These data were taken on May 18,1993 at an altitude of $20 \mathrm{~km}$.

than predicted on the basis of the rates of reactions (5) and (6) ${ }^{53}$ The nitric oxide density is calculated by assuming that NO is evenly mixed into the flow and that the measured velocity (sensed at the center of the duct after the water vapor detection axis) is representative of the bulk flow between the injector and the axes. The first assumption is clearly incorrect-there are, for instance, no NO inlets at the flow tube walls. Assuming a flat velocity profile at the injector this would result in higher calculated NO density in the center (and lower density at the wall). Furthermore, as the flow develops, drag reduces the velocity near the wall, and the flow rate in the center is accelerated. Because we measure the velocity $30 \mathrm{~cm}$ beyond the reaction zone, we overestimate the velocity and thus underestimate the NO density during the titration. Both these effects could explain why less NO is needed than expected.

That the two axes behave differently is clearly seen in Fig. 16. When normalized for the reaction time, the fall off in signal [due to reaction (6)] at axis 1 appears to occur faster than at axis 2 . This is similar to what has been observed in the ER-2 ClO experiment. ${ }^{66}$ These results can be rationalized by assuming non-uniform velocity and NO profiles across the fields of view of the detection axes.

Despite these inconsistencies, it is reassuring to note that the retrieved $\mathrm{HO}_{2}$ concentrations are equal at both axes $( \pm 5$ percent) and are independent of the bulk air flow rates ( \pm 5 percent for velocities between 40 and $100 \mathrm{~m} / \mathrm{s}$ ).

\section{Uncertainty in the retrieved $\mathrm{HO}_{2}$ densities}

Error in the rate constants used to infer the percent conversion of $\mathrm{HO}_{2}$ to $\mathrm{OH}$ will propagate into the determination of the $\mathrm{HO}_{2}$ mixing ratios. A sensitivity analysis shows that, within the uncertainty limits for reactions (5) and (6) given in a recent review, ${ }^{53}$ the peak conversion rate should be accurate to within 20 percent. Inhomogeneities in mixing of NO into the flow will result in a lower conversion efficiency of $\mathrm{HO}_{2}$ to $\mathrm{OH}$. The inference of the $\mathrm{HO}_{2}$ concentration is most sensitive to the relative rates of reactions (5) and (6),

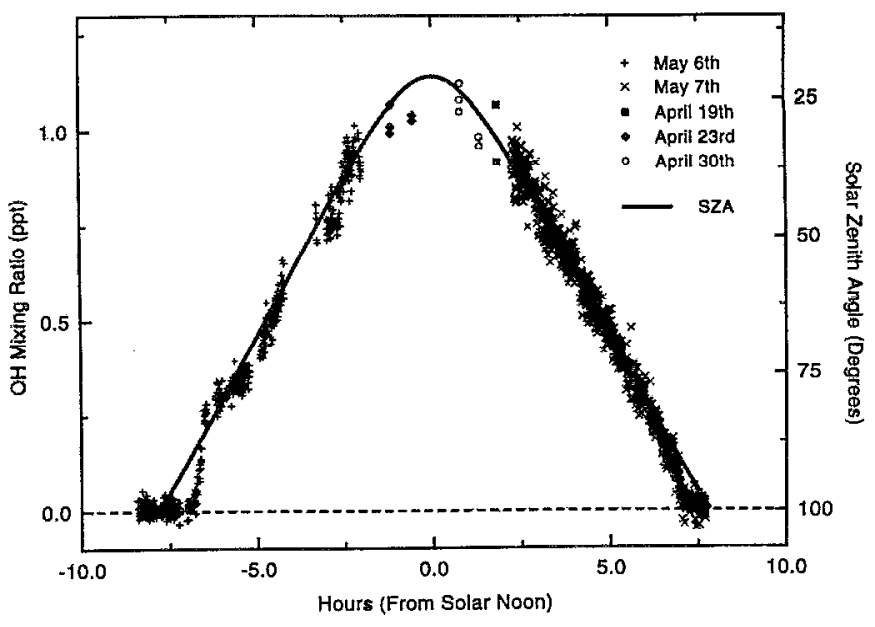

FIG. 17. The diurnal profile of $\mathrm{OH}$ was measured on the 6 th and 7 th of April 1993. The ER-2 was flying near $38 \mathrm{~N} 122 \mathrm{~W}$ at $18 \mathrm{~km}$ (Potential Temp. $=450-470 \mathrm{~K})$. Also shown are data taken on other days at the same altitude and potential temperature. The abrupt rise of the $\mathrm{OH}$ and $\mathrm{HO}_{2}$ mixing ratios at sunrise was a surprise.

which we measure directly in flight (see Fig. 16). The flight data suggest that this ratio is within $20 \%$ of the value suggested by DeMorc et al. ${ }^{53}$ We thus estimate that the inferred conversion efficiency (and thus our knowledge of the atmospheric ratio of $\mathrm{OH}$ to $\mathrm{HO}_{2}$ ) should be accurate to better than 25 percent. The absolute $\mathrm{HO}_{2}$ mixing ratio depends directly on the calibration of the instrument for $\mathrm{OH}$, and as a result, the net error for $\mathrm{HO}_{2}$ could be as high as 40 percent ( $2 \sigma$ ).

\section{SOME RESULTS}

Figure 17 shows the capability of the instrument. Data from two flights-May 6 and 7, 1993-are appended and plotted as a function of time. These data were taken during nearly level flight at $63,000 \mathrm{ft}$ as the ER-2 flew a "racetrack" pattern near NASA Ames Research center $(38 \mathrm{~N}$, $122 \mathrm{~W})$. Also shown is the solar zenith angle. $\mathrm{OH}$ is seen to exhibit a strong diurnal dependence. At sunrise, $\mathrm{OH}$ concentrations rose rapidly, which was a great surprise. Reactions (1) and (2) cannot explain this: The short wavelengths necessary for these processes are not available until the sun is higher in the sky (SZA $>80$ ). An unknown source of $\mathrm{OH}$ or $\mathrm{HO}_{2}$ is present in the early morning and points to deficiencies in our understanding of lower stratospheric $\mathrm{HO}_{x}$ chemistry. A few "spikes" are also apparent in the $\mathrm{OH}$ data. At the end points of the "race-track" the ER-2 often flew back through its own engine exhaust. These events were also characterized by elevated $\mathrm{CO}_{2}, \mathrm{H}_{2} \mathrm{O}$, and the oxides of nitrogen. ${ }^{67}$

\section{INTO THE TROPOSPHERE?}

On most flights no data were taken at pressures above $200 \mathrm{mb}$. During ascent, the delay in turn on prevented recording tropospheric data. During descent, the main closure valve was usually closed to prevent fouling of the optics from condensation. On a few occasions, however, the duct remained open during descent giving us a glimpse of the capabilities of the instrument to measure $\mathrm{OH}$ in the lower 


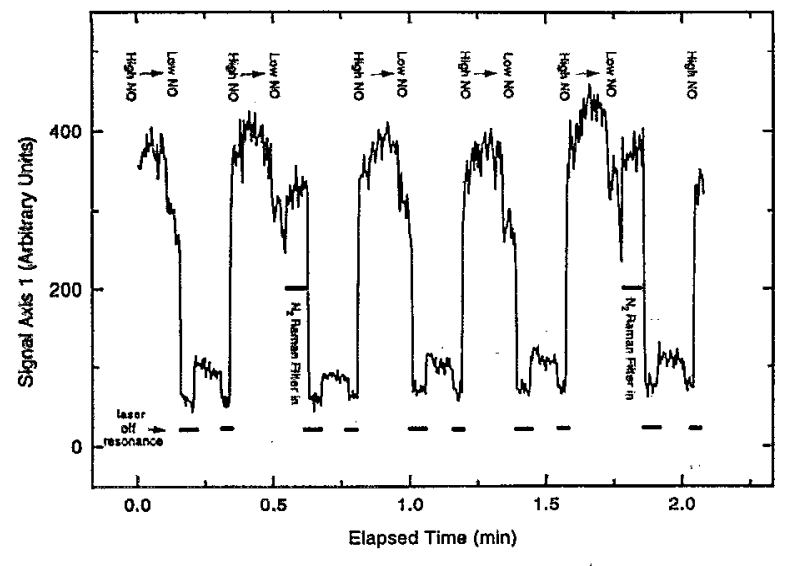

FIG. 18. Unaveraged 4 samples/sec signal in the troposphere during descent into Moffett field on April 18, 1993. The atmospheric pressure was increasing from approximately 400 to $500 \mathrm{mb}$ during this period. High signal-tonoise for both $\mathrm{OH}$ (small square wave, approximately 50 units) and $\mathrm{HO}_{2}$ are apparent.

atmosphere. Figure 18 shows some raw $4 \mathrm{~Hz}$ data taken on May 18, 1993 (the last flight in the SPADE measurement campaign) as the ER-2 descended into Moffett field at the NASA Ames Research Center. High signal rates are apparent even before any signal averaging: Interpretation of these results is, however, complicated. The air used to purge the NO from the injector is delivered at a constant mass flow rate. Although this is sufficient to fully remove the NO from the injector in the stratosphere (pressures $<200$.torr), in the lower atmosphere, a small amount of NO is leaking out of the injector during the period when $\mathrm{OH}$ measurements are being made. This is apparent in the raw data-the $\mathrm{OH}$ density in the duct is seen to fall during each measurement cycle. Additional evidence comes from comparing the signals at the two axes. $\mathrm{OH}$ concentrations at axis 2 are higher than at axis 1 due to the longer reaction times available for the residual NO to interact with the large concentrations of $\mathrm{HO}_{2}$ and other peroxy radicals. Additional uncertainty comes from the unknown production of $\mathrm{OH}$ by the laser at these altitudes. In the upper troposphere, however, it is known to be small. During one flight, $\mathrm{OH}$ measurements were made during the dark down to $10 \mathrm{~km}$. The water vapor mixing ratio was greater than $100 \mathrm{ppm}$. No $\mathrm{OH}(<0.05 \mathrm{ppt})$ was observed. The high signal rates and small background levels give us hope that precise and accurate tropospheric $\mathrm{OH}$ measurements will be achievable with the instrument. Changes in the instrument operation would correct the NO problem, and use of the chemical modulation technique could help quantify the extent of photochemical interference. Unfortunately, operational constraints on the ER-2 prevent the long tropospheric flights that may be necessary to adequately investigate the ability to make low altitude hydroxyl measurements.

The ER-2 $\mathrm{HO}_{x}$ instrument represents the culmination of a 15 year effort by our research group to measure the oddhydrogen radical concentration of the stratosphere. Over the next ten years, global surveys of lower stratospheric $\mathrm{HO}_{x}$ chemistry in conjunction with simultaneous measurements of other trace species will be required to address one of the pressing issues of our day: How will the anthropogenically produced changes in the atmospheric concentrations of trace gases affect the ozone layer. Confidence in the ability of models to predict these effects will only be built by providing a data base of measurements with which to test their ability to properly describe the present. The instrument described in this paper can provide high temporal and spatial measurements of $\mathrm{OH}$ and $\mathrm{HO}_{2}$ of sufficient accuracy to represent just such a test.

\section{ACKNOWLEDGMENTS}

We would like to thank the many individuals whose efforts led to the success of this experiment. At Harvard: E. Weinstock, A. Dessler, H. Michelsen, E. Thompson, T. Martin, E. Schomp, R. Mendelson, J. Canavan, D. Spillane, F. DeFreze, G. Graves, R. Heroux, K. Perkins, D. Chartrand, P. Guay, P. Rossi, J. Greer, and J. McDonough; At NASAAmes: S. Hipskind, E. Condon, and S. Wegener, J. Barrilleaux and the pilots of the ER-2. Cooperation with the Lockheed engineering staff, H. Kent, G. Prince, and R. York, is gratefully acknowledged. A special thanks to A. Schmeltekopf for his support before and help during the integration of the instrument onto the aircratt. This project would not have been possible without the pioneering work of R.M. Stimpfle. This work funded in part by the NASA HSRP Program with addition support from the NASA High Altitude Branch. P. O. Wennberg gratefully acknowledges personal support from NSF and Hughes Graduate Fellowships.

${ }^{1}$ Wm. H. Brune, Science 256, 1154 (1992).

${ }^{2}$ F. L. Eisele and J. D. Bradshaw, Anal. Chem. 65, 927A (1993).

${ }^{3}$ B. Weinstock, Science 166, 224 (1969).

${ }^{4}$ H. Levy II, Sciẹnce 173, 141 (1971).

${ }^{5}$ P. Crutzen, Pure Appl. Geophys. 106, 1385 (1973).

${ }^{6}$ D. R. Bates and M. Nicolet, J. Geophys. Res. 55, 301 (1950).

${ }^{7}$ Atmospheric Ozone 1985, WMO Global Ozone Research and Monitoring Project, Report 16 (World Meleorological Organization, Case Postale No. 5, Geneva 20, Switzerland; 1986).

${ }^{8} \mathrm{P}$. O. Wennberg et al. (unpublished).

${ }^{9}$ J. G. Anderson, J. Geophys. Kes. 76, 7820 (1971).

${ }^{10}$ J. G. Anderson, Geophys. Res. Lett. 3, 165 (1976).

${ }^{11}$ J. G. Anderson, H. J. Grassl, R. E. Shetter, and J. J. Margitan, Geophys. Res. Lett. 8, 289 (1981).

${ }^{12}$ R. L. De Zafra, A. Parrish, P. M. Solomon, and J. W. Barrett, J. Geophys. Res. 89, 1321 (1984).

${ }^{13}$ J. H. Park and B. Carli, J. Geophys. Res. 96, 22535 (1991).

${ }^{14}$ H. M. Pickett and D. B. Peterson, J. Geophys. Res. 98, 20507 (1993).

${ }^{15}$ W. A. Traub, D. G. Johnson, and K. V. Chance, Science 247, 446 (1990).

${ }^{16}$ R. A. Stachnik, J. C. Hardy, J. A. Tarsala, J. W. Waters, and N. R. Erickson, Geophys. Res. Lett. 19, 1931 (1992).

${ }^{17}$ D. Mihelcic, A. Volz-Thomas, H. W. Pätz, D. Kley, and M. Mihelcic, J. Atmos. Chem. 11, 271 (1990).

${ }^{18}$ W. S. Heaps and T. J. McGee, J. Geophys. Res. 90, 7913 (1985).

${ }^{10}$ W. S. Heaps and T. J. McGee, J. Geopliys. Res. 88, 5281 (1983).

${ }^{20}$ R. M. Stimpfle and J. G. Anderson, Geophys. Res. Lett. 15, 1503 (1988).

${ }^{21}$ R. M. Stimpfle, L. B. Lapson, P. O. Wennberg, and J. G. Anderson, Geophys. Res. Lett. 16, 1433 (1989).

${ }^{22}$ R. M. Stimpfle, P. O. Wennberg, L. B. Lapson, and J. G. Anderson, Geophys. Res. Lett. 17, 1905 (1990).

${ }_{23}$ P. O. Wennberg, R. M. Stimplle, E. M. Weinstock, A. E. Dessler, S. A. Lloyd, L. B. Lapson, J. J. Schwab, and J. G. Anderson, Geophys. Res. Lett. 17, 1909 (1990).

${ }^{24}$ C. C. Wang and L. I. Davis, Jr., Phys. Rev. Lett. 32, 349 (1974).

${ }^{25}$ C. C. Wang, L. I. Davis, Jr., C. H. Wu, S. Japar, H. Niki, and B. Weinstock, Science 189, 797 (1975).

${ }^{26}$ C. C. Wang, L. I. Davis, Jr., C. H. Wu, and S. Japar, Appl. Phys. Lett. 28, 14 (1975).

${ }^{27}$ D. D. Davis, W. Heaps, and T. McGee, Geophys. Res. Lett. 3, 331 (1976). 
${ }^{28}$ G. P. Smith and D. R. Crosley, J. Geophys. Res. 95, 16427 (1990).

${ }^{29}$ T. M. Hard, C. Y. Chan, A. A. Mehrabzadeh, and R. J. O'Brien, J. Geophys. Res. 97, 9785 (1992).

${ }^{30} \mathrm{Wm}$. H. Brune, E. M. Weinstock, and J. G. Anderson, Geophys. Res. Lett. 15, 144 (1988).

${ }^{31}$ P. T. Soderman, N. L. Hazen, and Wm. H. Brune, Aerodynamic Design of Gas and Aerosol Samplers for Aircraft. NASA Technical Memorandum 103854 (NASA, 1991).

${ }^{32} \mathrm{H}$. Schlichting, Boundary-Layer Theory, translated by J. Kestin (McGrawHill, New York, 1968).

${ }^{33}$ R. W. Wallace, Opt. Commun. 4, 316 (1971).

${ }^{34}$ P. S. Stevens, J. H. Mather, and W. H. Brune, J. Geophys. Res. 99, 3543 (1994).

${ }^{35}$ E. Fridell, Chem. Phys. Lett. 188, 487 (1992).

${ }^{36}$ J. U. White, J. Opt. Soc. Am. 32, 285 (1942).

${ }^{37}$ D. Koga (personal communication).

${ }^{38}$ A. Goldman and J. R. Gillis, J. Quant. Spectrosc. Radiat. Transfer 25111 (1981).

${ }^{39}$ E. E. Whiting, J. Quant. Spectrosc. Radiat. Transfer 8, 1379 (1968).

${ }^{40}$ B. Shirinzadeh, D. M. Bakalyar, and C. C. Wang. J. Chem. Phys. 82, 2877 (1985).

${ }^{41}$ E. C. Rea, Jr., A. Y. Chang, and R. K. Hanson, J. Quant. Spectrosc. Radiat. Transfer 37, 117 (1987).

${ }^{42}$ I. L. Chidsey and D. R. Crosley, J. Quant. Spectrosc. Radiat. Transfer 23, 187 (1980).

${ }^{43}$ J. J. Ter Meulen, W. A. Majewski, W. L. Meerts, and A. Dymanus, Chem. Phys. Lett. 94, 25 (1983).

${ }^{44}$ K. R. German, J. Chem. Phys. 63, 5252 (1975).

${ }^{45}$ K. R. German, J. Chem. Phys. 64, 4065 (1976).

${ }^{46}$ R. K. Lengel and D. R. Crosley, I. Chem. Phys. 68, 5309 (1978)

${ }^{47}$ P. M. Selzer and C. C. Wang, J. Chem. Phys. 71, 3786 (1979).
${ }^{48}$ I. S. McDermid and J. B. Laudenslager, J. Chem. Phys. 76, 1824 (1982).

${ }^{49}$ R. A. Copeland and D. R. Crosley, J. Chem. Phys. 84, 3099 (1986).

${ }^{50}$ J. Burris, J. J. Butler, T. J. McGee, and W. S. Heaps, Chem. Phys. 124, 251 (1988).

${ }^{51}$ R. A. Copeland, M. L. Wise, and D. R. Crosley, J. Phys. Chem. 92, 5710 (1988).

${ }^{52} \mathrm{~L}$. Williams and D. Crosley (personal communication).

${ }^{53}$ W. B. DeMore, S. P. Sander, D. M. Golden, R. F. Hampson, M. J. Kurylo, C. J. Howard, A. R. Ravishankara, C. E. Kolb, and M. J. Molina, Chemical Kinetics and Photochemical Data for Use in Stratospheric Modeling (JPL Publication, 1992), Evaluation Number 10.

${ }^{54}$ C. I. M. Beenakker, Spectrochimi. Acta 32B, 173 (1977).

${ }^{55}$ D. Klenerman and I. W. M. Smith, J. Chem. Soc., Faraday Trans. 2 83, 229 (1987).

${ }^{56}$ J. E. Spencer and G. P. Glass, Chem. Phys. 15, 35 (1976).

${ }^{57}$ H. W. Schrötter and H. W. Klockner, Topics in Current Physics (Springer, Berlin, 1979), Vol. 11.

${ }^{58}$ Wm. L. Dimptl and J. L. Kinsey, J. Quant. Spectrosc. Radiat. Transfer 21, 233 (1979).

${ }^{59}$ J. P. D. Abbatt and J. G. Anderson, J. Phys. Chem. 95, 2382 (1991).

${ }^{60}$ A. Mclloy and F. P. Tully, J. Phys. Chem. 97, 610 (1993).

${ }^{61}$ M. Dubey, P. O. Wennberg, and J. G. Anderson (unpublished).

${ }^{62}$ T. M. Hard, A. A. Mehrabzadeh, C. Y. Chan, and R. J. O'Brien, J. Geophys. Res. 97, 9795 (1992).

${ }^{63}$ A. Jörg, U. Meier, R. Kienle, and K. Kohse-Höinghaus, Appl. Phys. B 55, 305 (1992).

${ }^{64}$ R. K. Lengel and D. R. Crosley, J. Chem. Phys. 67, 2085 (1977).

${ }^{65}$ R. A. Copeland, M. J. Dyer, and D. R. Crosley, J. Chem. Phys. 82, 4022 (1985).

${ }^{66}$ R. M. Stimpfle (personal communication).

${ }^{67}$ D. W. Fahey et al. (unpublished). 